Review

\title{
Forward Osmosis: A Critical Review
}

\author{
Mehrdad Mohammadifakhr ${ }^{1}{ }^{10}$, Joris de Grooth ${ }^{1,2}$, Hendrik D. W. Roesink ${ }^{1}$ and \\ Antoine J. B. Kemperman ${ }^{1, *(D)}$ \\ 1 Membrane Science and Technology Cluster, Department of Science and Technology, Mesa+ Institute for \\ Nanotechnology, University of Twente, P.O. Box 217, 7500 AE Enschede, The Netherlands; \\ mehradmf@gmail.com (M.M.); j.degrooth@utwente.nl (J.d.G.); h.d.w.roesink@utwente.nl (H.D.W.R.) \\ 2 Films in Fluids, Faculty of Science and Technology, Mesa+ Institute for Nanotechnology, University of \\ Twente, P.O. Box 217, 7500 AE Enschede, The Netherlands \\ * Correspondence: a.j.b.kemperman@utwente.nl; Tel.: +31-534-892-956
}

Received: 21 February 2020; Accepted: 21 March 2020; Published: 30 March 2020

\begin{abstract}
The use of forward osmosis (FO) for water purification purposes has gained extensive attention in recent years. In this review, we first discuss the advantages, challenges and various applications of FO, as well as the challenges in selecting the proper draw solution for FO, after which we focus on transport limitations in FO processes. Despite recent advances in membrane development for FO, there is still room for improvement of its selective layer and support. For many applications spiral wound membrane will not suffice. Furthermore, a defect-free selective layer is a prerequisite for FO membranes to ensure low solute passage, while a support with low internal concentration polarization is necessary for a high water flux. Due to challenges affiliated to interfacial polymerization (IP) on non-planar geometries, we discuss alternative approaches to IP to form the selective layer. We also explain that, when provided with a defect-free selective layer with good rejection, the membrane support has a dominant influence on the performance of an FO membrane, which can be estimated by the structural parameter (S). We emphasize the necessity of finding a new method to determine $S$, but also that predominantly the thickness of the support is the major parameter that needs to be optimized.
\end{abstract}

Keywords: forward osmosis; membrane support; structural parameter; concentration polarization

\section{Introduction}

The growing world population and their increasing environmental burden are creating a need for more drinking water as well as a demand for cleaner energy sources and a reduction of fossil fuel use $[1,2]$. This is boosting research in the water and energy sectors $[3,4]$. The diminishing natural freshwater resources are not able to keep up with the demand [5], hence researchers are looking at ways to produce more freshwater from seawater and other resources for household consumptions $[6,7]$. Distillation, membrane filtration (notably through reverse osmosis (RO)) and other methods have started to fulfill this additional need for fresh water [3]. Desalination with RO membranes seems the most preferred approach [8], but suffers from a high electricity consumption. Yet, to the best of our knowledge, $\mathrm{RO}$ is still one of the most energy-efficient desalination processes, as its cost is severely affected by the thermodynamics of the separation process [9]. It is important to emphasize that water and energy production (electricity as well as fuel) are linked; this is known as the "water-energy nexus" [10]. Electricity is used to produce freshwater, while on the other hand, an enormous amount of freshwater is actually consumed for cooling purposes in power generation and for the extraction of fossil fuels $[4,11]$. Therefore, there is a need for more sustainable water production methods that can use other energy sources than electricity [12]. For this, forward osmosis (FO) is a good candidate, as it 
uses the osmotic pressure of a high solute concentration as an energy source. For some applications it is considered as an alternative for reverse osmosis [13-15].

Forward osmosis is the movement of water through a semi-permeable membrane due to an osmotic pressure gradient [14]. In the FO process, a semi-permeable membrane separates two solutions with different concentrations. The concentrated solution is called "draw" and the diluted solution "feed", referring to the nature of the process in which the high-salinity solution "draws" the water from the low-salinity solution, which "feeds" water to the process [16]. The osmotic pressure difference between the two solutions is the driving force that causes water to migrate from the feed side to the draw side [14,15,17-19]. In contrast, for RO a hydrostatic pressure greater than the osmotic pressure is applied to the draw side, causing water to flow from the concentrated side to the more diluted side. Figure 1 is a schematic depiction of the FO and RO processes.

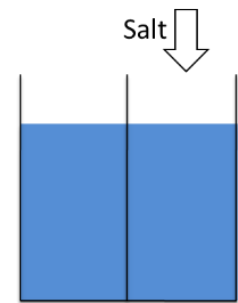

Equilibrium

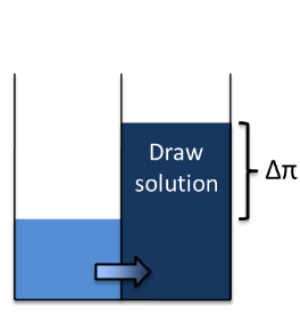

FO

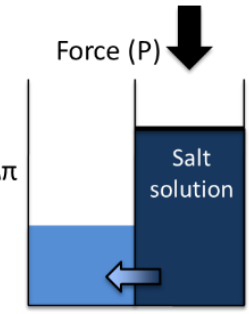

$\mathrm{RO}(\Delta \mathrm{P}>\Delta \pi)$

Figure 1. Schematic of forward osmosis (FO) and reverse osmosis (RO); $\Delta \pi$ is the osmotic pressure gradient.

Despite the obvious advantages of FO, it has some complications that limit the applicability of FO. A proper acknowledgment and understanding of these limitations will allow for a better utilization of this technology. One of the main challenges is finding suitable membranes that yield a large water flux and a minimal reverse salt flux [20].

While there have been a couple of review papers in recent years concerning the basic principles of FO [21-24], draw solutions [22,25-31], applications [21,25,27,32-39], (bio)fouling [22,25,26,30,40-46], membrane fabrication $[19,23,30,35,39,43,47,48]$, or upscaling $[49,50]$, we, for the major part of this review, discuss the challenges of FO evidences from various literatures to prove the unreliability of the existing structural parameter approaches. In addition, we will highlight that, beyond a certain water permeability, the true bottleneck is the mechanical support of the membrane instead of the selective membrane layer. We further emphasize that the thickness of the support is of the most importance for improving the FO performance.

\subsection{Advantages of Forward Osmosis}

There is a common belief that one of the advantages of FO over pressure-driven membrane processes is its low energy consumption owing to the lack of any applied hydraulic pressure. However, FO actually uses the same amount of energy, if not more. The important difference is the source of energy used by FO, which can be chosen from low-cost energy sources.

In addition, it has been claimed that the absence of an applied hydraulic pressure leads to less fouling of FO membranes and higher fouling reversibility [12,17,51-62]. However, the low fouling behavior is partly due to the lower fluxes typically obtained in FO [63]. The use of hydraulic pressure causes a convective flow to the membrane surface, which leads to higher local concentrations and thus to more fouling, but this convective flow happens in FO as well. Therefore, relating the reduced fouling in FO processes to only the absence of hydraulic pressure is incorrect as Nguyen et al. have shown [64]. They demonstrated that there is a critical (threshold) flux for each type of FO membrane, beyond which fouling starts to occur. Inherently, fouling in FO occurs in a similar way as fouling in RO, i.e., as a result of chemical and hydrodynamic interactions [13,57]. However, the effect of fouling 
on FO performance is typically far less severe as the fouling layers are less dense and the fouling is therefore more reversible [52,62] (Figure 2).
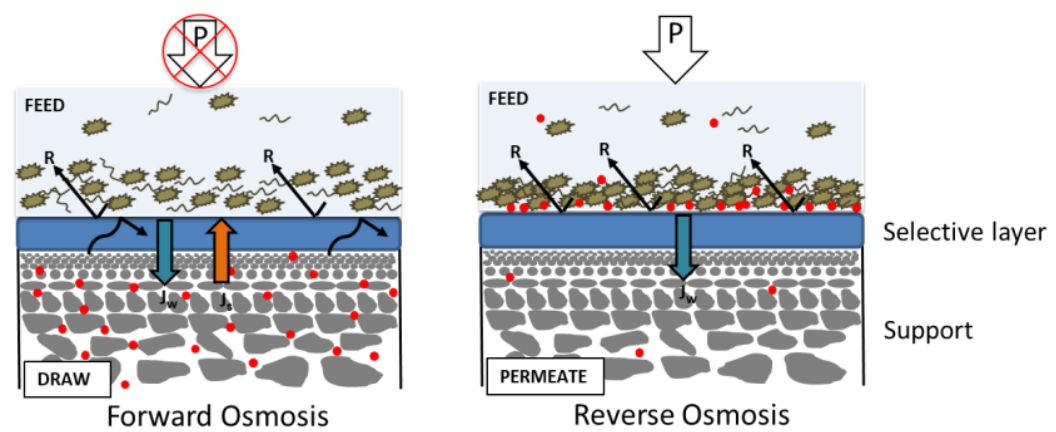

Figure 2. Schematic of fouling in forward osmosis (FO) and reverse osmosis (RO) processes.

As a result of its lower fouling tendency, FO is capable of recovering clean water from challenging and highly fouling sources without extensive pretreatment [29]. In addition, the lower fouling tendency makes cleaning easier and less frequently required, which extends the membrane lifetime [4].

Another advantage of $\mathrm{FO}$ is the high selectivity of $\mathrm{FO}$ processes relative to $\mathrm{RO}$ processes. Xie et al. [65] attributed this to a phenomenon called retarded forward diffusion of solutes. This basically means that the reverse salt flux in FO hinders the pore diffusion of feed solutes, leading to the high rejection of feed solutes [65]; see Figure 3.

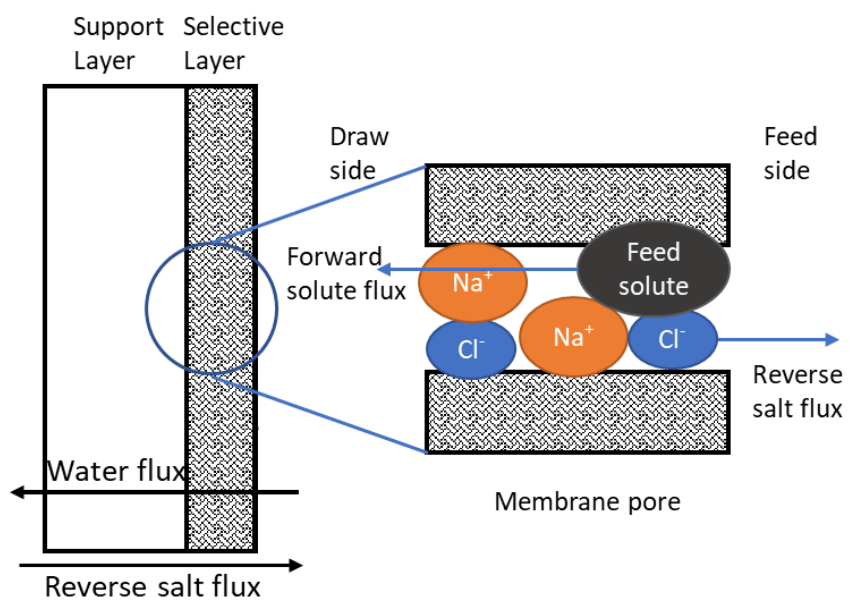

Figure 3. Schematic of the reverse flux of the draw solutes retarding forward diffusion of feed solutes in the FO process; after Xie et al. [65].

Similarly, Liu et al. [66] found higher rejection of bisphenol A in an FO process (99.5 $\pm 0.1 \%)$ than in $\mathrm{RO}(97.3 \pm 1.6 \%)$ which they also attributed to the reverse salt flux that hinders the permeation of micropollutants from feed to the draw solution. This opposite movement of the draw solute retards the diffusion of the feed particles towards the draw solution, leading to higher selectivity (rejection) in FO than RO.

\subsection{Disadvantages of Forward Osmosis}

It is important to realize that the final product of the FO process is not clean water unlike in most other water purification processes, but a diluted draw solution. Therefore, in most cases, FO needs to be combined with a second separation step (often RO) to recover the draw solution and produce clean water $[29,67]$. FO can be therefore only truly be regarded as consuming less energy if the draw solution does not need to be regenerated [68], such as in dewatering processes when using seawater or the 
desalination brine as a low-cost draw solution [69] and in fertilizer dilution applications when using seawater as feed solution and the concentrated fertilizer as the draw solution [70]. However, in many applications a posttreatment step of the draw solution is necessary. This frequent need for an additional step to produce clean water has created some confusion regarding the electricity consumption of FO [17]. In fact, FO-RO units are reported to consume more electricity than a standalone RO unit in seawater desalination [71].

Finding a suitable draw solute that can produce a high osmotic pressure at a sufficiently high solubility in water and is easy to recover or regenerate is challenging. Cai et al. [72] have published an extensive review of draw solutions and their intricacies. Selection of the draw solution is usually a trade-off; while it is essential to have highly diffusive draw solutes to maintain the high osmotic pressure inside the support, this extreme diffusivity also leads to leakage to the feed solution (the reverse salt flux). On the other hand, using a solute with low diffusivity results in a decrease in osmotic pressure inside the support, which causes the main downside of FO, namely internal concentration polarization (ICP). Therefore, there must be a direct correlation between draw solute diffusion coefficient (diffusivity) and ICP of the support in FO process which is not extensively studied in the literature. Yet this drop in osmotic pressure due to low diffusivity of the draw solute significantly affects the water flux in FO [13,56,73-77]. One is referred to Section 2.1 for more on challenges in selecting a suitable draw solution and Section 2.2.2 for more details on ICP and its effects.

\subsection{Applications of Forward Osmosis}

FO can be used in a broad range of applications such as wastewater treatment [32,78-80], seawater desalination [81-84], dewatering and concentration in the food industry [85-93], and the removal of dissolved metals [94-97]. The geometry of the FO membrane should be chosen wisely in accordance with the intended application. Particularly in treating highly viscous solutions or solutions with a high solute loading such as the food industry or in wastewater treatment, a hollow fiber geometry is preferred over flat sheet based (spiral wound) membranes. It is well established that the hollow fiber geometry has a low fouling tendency $[98,99]$, suitable for these applications. Furthermore, hollow fiber membranes have a larger surface area per unit volume as compared with flat sheets [100]. The most notable FO applications shortly will be discussed below.

\subsubsection{Wastewater Treatment}

FO has been utilized in municipal wastewater (sewage) treatment systems [101]. FO membrane systems are capable of rejecting large ions as well as concentrating sewage up to a factor of ten to fifteen [78]. FO can also be used in combination with RO in a hybrid process, in which FO uses a wastewater stream to produce high-quality water to dilute seawater prior to an $\mathrm{RO}$ step. In another study [80], a forward osmosis-membrane distillation hybrid process was used to remove tetracycline from wastewater, with a rejection of $99.9 \%$ and a water recovery of $15-22 \%$. In addition to water recovery, FO can be used in wastewater treatment for nutrient and energy recovery [32]. Examples of these recoveries include biogas production and recovery of nutrients such as phosphate, ammonia, and potassium [32].

Many of these FO processes in wastewater treatment become viable when high process recoveries are obtained. If very excessive pre-treatments steps of the to be treated stream should be avoided, hollow fiber or tubular membranes seem the be to best geometry for these applications.

\subsubsection{Desalination}

One of the first studies describing the use of FO in water desalination was published in 1975 [81]. This paper confirmed that desalination of Atlantic Ocean seawater was possible by using an FO membrane with a glucose solution as the draw solution. Application of an FO-NF (nanofiltration) hybrid process in brackish water desalination instead of a stand-alone $\mathrm{RO}$ unit resulted in less fouling in the NF and a high water recovery ( $>90 \%)$ due to the addition of the FO step [82]. McCutcheon et al. [83] 
investigated the possibility of using FO for seawater desalination with 0.05 to $2 \mathrm{M} \mathrm{NaCl}$ as feed solution. Salt rejections of $95 \%$ to $99 \%$ were achieved in most of the tests, using different ammonia-carbon dioxide draw solution concentrations. In another study, a flat-sheet cellulose tri-acetate FO membrane was used in water desalination, yielding a high water flux and high salt rejection (over 95\%) with ammonium bicarbonate as draw solution [84].

In these studies [81-84], FO displayed a high rejection towards $\mathrm{NaCl}$ and little fouling. However, to obtain a reasonable water flux, the draw concentration should be factors higher than that of seawater in order to generate a sufficient osmotic pressure difference. In addition, the final product is not clean water but a diluted draw solution, which needs an additional step to recover both water and draw solute. It is important to note that this secondary treatment step thermodynamically can never cost less energy as the initial desalination step. Therefore, FO is only viable for desalination if the concentrated draw solution can be directly used (negating the need of a secondary treatment step), or if the concentrated draw solution can be recovered with lower-quality (or residual) energy.

\subsubsection{Food-Related Applications}

In the food industry, a crucial process step is often to dewater liquid foods to improve product stability as well as to minimize packaging, storage, and transportation costs. The most common technique used in liquid food concentration is vacuum evaporation, but the high temperature applied in this technique results in the degradation of temperature-sensitive components such as vitamins, flavor molecules as well as phytochemicals [102,103]. FO is a promising alternative for concentrating liquid foods, food ingredients and natural colorants to high levels [85-87] at ambient conditions. Popper et al. [88] were the pioneers in using FO with polymeric membranes to concentrate fruit juices. In another study, extracted anthocyanin pigment from rose petals was tested for further concentration by thermal evaporation, freeze-drying, and forward osmosis; the FO concentration process showed less degradation of anthocyanin than other the two methods [89]. This emphasizes the main advantage of FO in these applications: the mild process conditions in FO are beneficiary for many sensitive components. Melanoidins (colorants and antioxidants) have been concentrated with FO using aquaporin-based biomimetic membranes; the rejection of melanoidins and other organics was above $85 \%$ with a water recovery of $70 \%$ [90]. Wang et al. [91] utilized FO as an alternative method for concentrating whey and achieved a relatively high water flux, a high rejection of whey (>99.97\%) and a low reverse solute flux. Madhumala et al. [92] looked into the feasibility of fructose concentration by using $\mathrm{FO}$ and found significant economic advantages when a $\mathrm{NaCl}$ draw solution was chosen, as this improved the production of sugar crystals by $16 \%$ to $20 \%$. FO has also been proven useful in oil concentration by water recovery from emulsions, showing a high water flux and a rejection of $99.9 \%$ towards the emulsion [93].

FO appears to be a viable option for dewatering purposes in the food industry due to the mild conditions and because the final product is often not water, but the concentrated stream. Therefore, the second step of water/draw recovery might not be needed. FO's low fouling tendency is also a big benefit in the food industry in which major fouling of the membranes can be expected [104]. Inherently, a dewatering step aims at a high overall recovery, or a high concentration factor. This means that, similar to wastewater applications, hollow fiber or tubular membrane geometries are preferred.

\subsubsection{Specific Contaminants Removal}

FO typically offers higher rejection of a broad range of contaminants compared to RO processes, due to its retarded forward diffusion of the ionic species from the draw solute [65] (see also Figure 3). One study looked at the possibility of removing foulants from coal seam gas by FO and found that the dissolved organic carbon, denosine tri-phosphate and major inorganic scalants ( $\mathrm{Ca}, \mathrm{Mg}$ and silica) in the coal seam gas feed were removed substantially [94]. Moreover, FO showed almost 7.5 times higher rejection of urea as compared to the $\mathrm{RO}$ rejections [105]. In another study [66], FO was investigated 
as a potential process for rejection of micropollutants; a higher rejection of bisphenol A in FO mode $(99.5 \pm 0.1 \%)$ than in the RO mode $(97.3 \pm 1.6 \%)$ were obtained.

In summary, operating in FO mode typically shows better performance in rejecting small solutes such as urea and micropollutants than operation in RO mode. This makes FO also interesting for applications where small solutes need to be removed to a large extent.

\section{Challenges}

Despite the recent progress in FO research, there are several challenges remaining. Very important in the FO process is the draw solution, as this manifests the driving force for the water flux [48]. An optimal draw solution should produce a high osmotic pressure and be easy to regenerate. Another crucial challenge in FO is internal concentration polarization (ICP), which results in a lower effective driving force and subsequently lower water fluxes. In selective-layer-facing-feed-solution (FO) mode, ICP causes the osmotic pressure gradient across the selective layer to be much lower than the bulk osmotic pressure gradient due to draw solute dilution in the membrane support. Research into optimizing membranes for FO started only a decade ago and, in the meantime, mostly thin-film composite RO membranes have been used in FO. These RO-type membranes contain a support layer designed to withstand the high-pressure conditions in RO. This thick support is the main reason for severe ICP, so thinner supports should lead to better FO membranes [12]. Alternatives for the currently available polymeric FO membranes need to be developed to improve the performance of FO processes further [106]. Such membranes should be highly permeable and selective, with minimal ICP [107].

In fact, the water flux of the FO membranes is influenced by both the water permeance of the selective layer (A value) and by the ICP of the support layer. However, it was shown in a study from Werber et al. [108] that the A value has only a significant influence on the osmotic water flux for values up to $1 \mathrm{~L} \mathrm{~m}^{-2} \mathrm{~h}^{-1} \mathrm{bar}^{-1}$ and the ICP effect is overshadowed by the A value in this region. On the other hand, once the water permeance (A) is higher than $1 \mathrm{~L} \mathrm{~m}^{-2} \mathrm{~h}^{-1} \mathrm{bar}^{-1}$, the influence of ICP on the water flux is much less limited by the A value. At these permeances the major transport limitation is not in the separation layer anymore [108]. It is worth to mention that fabrication of selective layers with a water permeance (A) of $1\left(\mathrm{~L} \mathrm{~m}^{-2} \mathrm{~h}^{-1} \mathrm{bar}^{-1}\right)$ is typically not challenging, as the scientific community can learn from their experiences of seawater and brackish water desalination membrane development. However, ICP is not an issue for these applications and thus current membranes have not been designed to deal with ICP. Therefore, we argue that the major effort in FO membrane development should be put on the optimization of the support than on improving the selective layer for FO membranes.

\subsection{Draw Solution}

In $\mathrm{FO}$, the draw solute is a crucial factor as its task is to produce the actual driving force for water transport through the membrane. In addition, a good draw solution is one that can be regenerated easily, offering a reduction in process costs [109]. The most challenging part of the draw solute is that it should have a strong affiliation with water molecules either via hydration or ionization to generate a high osmotic pressure. However, this inherently makes separating the solute from water in the regeneration step very challenging.

In addition, a suitable draw solute must meet other requirements such as causing no damage to the FO membrane, low toxicity, minimal reverse draw solute flux, low viscosity, high diffusivity, chemically stability and low costs [72,109]. Especially, the viscosity and diffusivity are of high importance due to their direct influence on water flux, as the ICP will be reduced when the draw solute can diffuse into the support very quickly. Cai et al. [72] categorized the draw solutes into non-responsive and responsive ones. Non-responsive draw solutes are those draw solutes of which the affinity for water molecules does not change at different temperatures, $\mathrm{pH}$ values, in electromagnetic fields or when exposed to light. Non-responsive draw solutes include inorganic salts, polymers, and organic molecules. Among the fourteen common inorganic salts, $\mathrm{KCl}$ was found to show the highest water flux in a study by Achilli et al. [110]. In addition to inorganic salts, organic salts with molecular weights between 100 
to $1000 \mathrm{Da}$ can be good options because they show less reverse salt permeation. However, organic salts are more expensive and they are less diffusive than inorganic salts such as $\mathrm{NaCl}$. This slower diffusion into the support leads to more severe ICP which is unfavorable for FO. For FO membranes with a defect-free and highly selective layer, $\mathrm{NaCl}$ is one of the most attractive draw solutes due to its small ion sizes and its high diffusivity into the support.

Responsive draw solutes are those of which the water affinity significantly changes in response to different stimulants such as temperature, $\mathrm{pH}$, light and electric or magnetic fields. This ability in potential makes a responsive draw solution easier to recover. Responsive draw solutions can be nanoparticles, hydrogels, salts precipitable via metathesis, soluble gases or volatile liquids, polarity-switchable solutes, and thermally responsive molecules [72]. Since a further discussion of the draw solution concept is beyond the scope of this article, we refer the interested readers to the detailed review by Cai et al. [72]. More general information about draw solutions is available elsewhere $[109,111,112]$. It is important to realize that, although the recovery of the draw can be achieved easier with a responsive draw, it will still require significant amounts of energy (related to the osmotic pressure of the draw). This means that responsive draw solutes do not require less energy to be recovered, but cheap or waste types of energy can be used (e.g., residual heat).

\subsection{FO Membrane}

An FO membrane consists of a support structure and a selective layer. While the support provides mechanical stability, the task of the selective layer is to reject particles and solutes from both feed and draw sides. Next to the permeance, the reverse permeation of the draw solute is the most challenging issue with regard to the selective layer, as it affects membrane fouling, osmotic pressure loss, and water flux [62]. On the other hand, the support suffers from ICP which lowers the water flux. A support's degree of ICP is indicated by the so-called structural parameter $\mathrm{S}$, where a high $\mathrm{S}$ value results in high amounts of ICP and subsequently lower water fluxes. The value of $S$ parameter can never be lower than the thickness of the support.

In order the illustrate the importance of both the structural parameter and the membrane permeance, we compared the data from studies on several hollow fibers FO membranes. The different results are grouped in membranes with a low permeance $\left(\mathrm{A}<0.5 \mathrm{~L} \mathrm{~m}^{-2} \mathrm{~h}^{-1} \mathrm{bar}^{-1}\right)$, medium permeance $\left(0.5<\mathrm{A}<2.0 \mathrm{~L} \mathrm{~m}^{-2} \mathrm{~h}^{-1} \mathrm{bar}^{-1}\right)$ and a high permeance $\left(\mathrm{A}>2.0 \mathrm{~L} \mathrm{~m}^{-2} \mathrm{~h}^{-1} \mathrm{bar}^{-1}\right)$. In addition, we added the theoretical expected flux based on the membrane permeance and some data on commercial flat sheet membranes for a comparison [113]. The analysis is given in Figure 4. What becomes evident is that even with a high permeance, low fluxes are obtained if the structural parameter of the support is too high. Only at lower $\mathrm{S}$ values, the membrane permeance substantially does contribute to the obtained water flux. Still, for very low permeances $\left(\mathrm{A}<0.5 \mathrm{~L} \mathrm{~m}^{-2} \mathrm{~h}^{-1} \mathrm{bar}^{-1}\right)$ no high water fluxes are expected at all. The analysis also shows that several hollow fiber membranes already perform similar or even outperform the commercial flat sheet membranes. The two commercial flat sheet membranes presented in Figure 4 show different $S$ values, even though these are the results from the same membranes. Bui et al. determined the water flux and structural parameters of two membranes under different process conditions [113], and showed that, with the same osmotic driving force, the results very much depend on the applied crossflow velocity. These results highlight the difficulties in comparing different membranes solely based on the obtained osmotic flux and subsequently make it difficult to define guidelines for the development of (hollow fiber) FO membranes. 


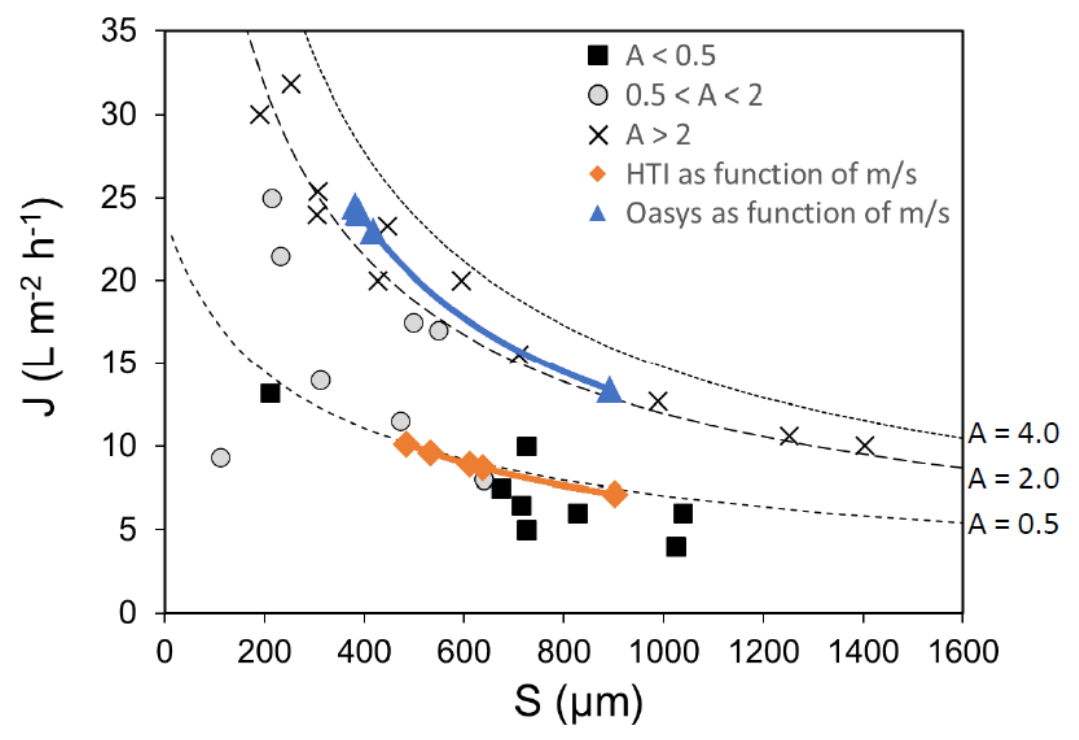

Figure 4. Correlation between determined the $S$ parameter and forward osmosis flux for different A ( $L$ $\mathrm{m}^{-2} \mathrm{~h}^{-1}$ bar $^{-1}$ ) values. The data from hollow fiber membranes gathered from literature ([114-130]) for FO mode with $1 \mathrm{M} \mathrm{NaCl}$ as a draw solution. Data from the HTI and Oasys membranes for $1 \mathrm{M}$ $\mathrm{NaCl}$ at different crossflow velocities (extracted from [113]). The dotted lines represent the theoretically expected fluxes for membrane permeances of 4.0,2.0, and $0.5\left(\mathrm{~L} \mathrm{~m}^{-2} \mathrm{~h}^{-1} \mathrm{bar}^{-1}\right)$ respectively based on their $S$ parameter.

In general, an ideal FO membrane must give a high water flux, a high rejection towards both feed and draw solutes and a reasonable mechanical strength. Therefore, the main objectives that govern FO membrane design are:

i. Have at least a water permeability of $>1 \mathrm{~L} \mathrm{~m}^{-2} \mathrm{~h}^{-1} \mathrm{bar}^{-1}$;

ii. Lowering the structural parameter of the support as much as possible;

iii. Increasing the selective layer's rejection of the draw solute to maintain the osmotic pressure difference [17].

\subsubsection{Selective Layer}

The selective layer normally is a thin layer that determines the membrane's separation properties. In pressure-driven processes, the mass transfer resistance principally is dictated by this layer, whereas in FO, both the support and the selective layer affect mass transport.

There are different methods to manufacture a membrane with a selective layer, such as interfacial polymerization (IP), layer-by-layer assembly (LbL), conventional phase inversion (asymmetric membranes), blending and surface grafting. Since the driving force in FO is the osmotic pressure difference, the FO membrane requires a highly rejecting selective layer to maintain this high driving force, otherwise the draw and feed solutes will quickly penetrate across the membrane and reduce the osmotic pressure difference [23]. Notably thin-film composite (TFC) membranes prepared via IP are promising in terms of high salt rejection and high water permeability [131]. This is at least partly due to the fact that IP is a proven technology for RO membranes, which means that extensive research and optimization already have taken place.

Thin-Film Composites Membranes by Interfacial Polymerization

TFC membranes have a thin polyamide layer as the selective layer. The promising results of TFC membranes in RO encouraged researchers to utilize them for FO applications as well. There are various ways to construct these membranes. Emerson et al. introduced the concept of interfacial polymerization (IP) in 1959 [132]. In the IP process, two highly reactive monomers are dissolved in 
two immiscible liquids. The reaction takes place at the liquid-liquid interface, which leads to the formation of a thin film [133]. Application of an IP coating on membranes was first reported by Cadotte et al. [134], who coated a microporous polysulfone support layer via IP, which resulted in $99.6 \%$ rejection toward $\mathrm{NaCl}$.

Commonly used monomers in IP are a variety of nucleophile reactants (usually multifunctional amines) and electrophile reactants (usually multifunctional acid chlorides), among which m-phenylenediamine (MPD) and trimesoyl chloride (TMC) are most popular [135]. These two monomers solutions are introduced on top of the support where the amidation reaction occurs, usually in the organic phase, to form a polyamide (PA) layer [39,136] (see Figure 5).

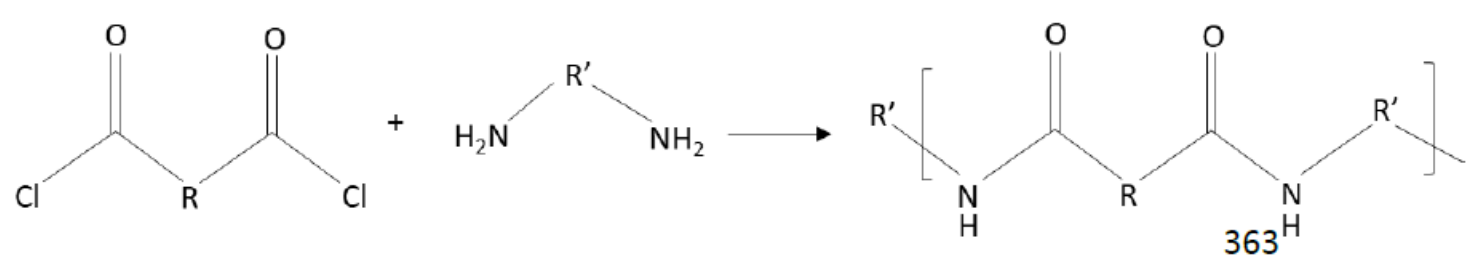

Figure 5. Polyamide formation via reaction between a two-acyl chloride monomer and a two-amine group monomer (after [135]).

The IP process consists of three different kinetic stages: Primary film formation, followed by slower polymerization and finally diffusion-limited growth [137]. The resultant TFC layer is non-uniform, which makes it difficult to characterize it by only one parameter such as charge or local polymer density, as these parameters change over the thickness of the layer $[138,139]$.

The ultimate characteristics of the thin film (molecular weight, surface roughness, and layer thickness) depend on the choice of the monomer, diffusivity, concentration, reactivity, and solubility [135]. In addition, the support's surface properties like roughness, pore size, porosity, and hydrophilicity also play significant roles in shaping the final characteristics of the thin film [140]. These properties affect wetting; proper wetting is crucial for producing a stable and suitable interface [140]. In principle, a hydrophilic surface with a pore size between 1 and $100 \mathrm{~nm}$ is considered optimal for the IP reaction on the support surface. For example, Singh et al. [141] investigated the influence of the support's pore size on the polyamide layer. They chose two polysulfone supports having an average pore size of $70 \mathrm{~nm}$ and $150 \mathrm{~nm}$ and found that the TFC-coated support with the smaller pore size had a thicker selective layer due to reduced penetration of polyamide into the support's pores and thus a greater salt rejection efficiency than its opener counterpart. However, a thicker polyamide layer leads to a lower water flux as well; thus, there is always a trade-off between water flux and salt rejection that must be considered for different applications.

Moreover, other parameters such as experimental conditions (concentration of the monomers, humidity, reaction time of monomers, drying time, level of skills and experience) were found to influence the morphology and characteristics of the formed polyamide layer [142,143]. As a result, even IP on the same supports can result in different selective layer characteristics due to both slight differences in the support's surface properties and the high sensitivity of the IP process. In summary, the high sensitivity of IP to experimental conditions $[144,145]$ and the support's surface properties $[114,140,141]$ can lead to shortcomings such as delamination [146] and lower reproducibility.

This is especially much more challenging when an IP is applied on the inner surface of hollow fibers. This is mainly due to the spherical geometry of the hollow fibers which makes the liquid-liquid interface needed for a proper IP challenging to control. Unlike their flat-sheet counterparts, gravity cannot aid in the establishment of a proper liquid-liquid interface. Furthermore, the drying step in between application of the two monomers used for IP is very important which influences the reproducibility and success of the nascent PA layer fabrication. While this could be done easily, e.g., by the use of a rubber roller for flat sheets, the drying has to be done by air purge for hollow fibers which does result in more frequent residual drops. These residual drops affect a proper liquid-liquid interface 
leading to defects in the PA layer. Moreover, pressure differences resulting from hydrodynamic flow differences along the hollow fiber membrane during the application of the layer may also lead to a different degree of penetration of the IP layer in the porous support along the fiber. These main drawbacks mean that, especially for hollow fiber supports, alternatives to IP-based layers need to be developed.

On the other hand, there are also advantages associated with TFC membranes. The main advantage is their high permeability and resistance against biodegradation relative to other commonly used FO membranes like cellulosic membranes [147]. The dense and thin polyamide layer of TFC membranes results in reasonable selectivity and water flux, and this can be further improved by incorporating carbon nanotubes [148,149] or aquaporins [150-152] in the layer. Another advantage of TFC membranes is that the properties of the support and the selective layer can be individually optimized to achieve the desired selectivity and permeability. When developing alternatives for IP, e.g., as necessary for hollow fiber supports, it is important to match the selectivity of the IP layers to ensure process selectivity and to not lose the draw solute during membrane operation.

Layer-by-Layer Assembly

Layer-by-layer assembly (LbL) is an alternative way to coat supports. It is a relatively new technique, which recently began attracting attention for FO membrane fabrication as well [153-156]. In an LbL assembly, oppositely charged layers (polyelectrolytes) are alternately deposited on top of a charged support to form a thin selective film.

Several advantages are associated with LbL based membranes. Firstly, LbL is a highly flexible and tunable membrane preparation technology due to the control on the number of layers that can be added as well as the possibility of using various types of polyelectrolytes (PE) [157]. In addition, LbL is a simple method that requires no sophisticated instruments and it can be used with any type of surface geometry regardless of shape and size as there is no need for a liquid-liquid interface. The application of LbL has already been shown to be successful on hollow fibers [158]. Moreover, this method is more sustainable as it uses polar solvents like water. Finally, LbL can also be used to create an ultra-thin defect-free layer [157]; this increases membrane permeability. These ultra-thin layers show good thermal stability and high solvent resistance [159].

The drawback of LbL-based membranes is the low rejection of very small draw solutes (notably $\mathrm{NaCl})[160,161]$. This limits the choice of draw solutions in the application of these membranes. To the best of our knowledge, there are only a few studies in which a $\mathrm{NaCl}$ rejection above $85 \%$ was achieved with LbL-based membranes [154,155,162].

Several studies utilized LbL membranes for FO applications and most indeed did not use $\mathrm{NaCl}$ as draw solute for FO performance determination [153,154,163,164]. Saren et al. [153] fabricated one of the first LbL-based FO membranes by using poly (allylamine hydrochloride) (PAH) and poly(sodium 4-styrene-sulfonate). Their three-bilayer membrane showed a water flux of 15,20 , and $28 \mathrm{~L} \cdot \mathrm{m}^{-2} \cdot \mathrm{h}^{-1}$ using $0.1,0.5$, and $1.0 \mathrm{M} \mathrm{MgCl}_{2}$ as draw solution, respectively. They chose $\mathrm{MgCl}_{2}$ instead of $\mathrm{NaCl}$ in view of the slightly larger radius of the hydrated $\mathrm{Mg}^{2+}$ ion. They improved their LbL-based FO membrane further by cross-linking the layer with glutaraldehyde. The cross-linked LbL membranes showed better $\mathrm{MgCl}_{2}$ rejection and consequently a lower reverse salt flux, and also a lower water flux [154]. In another study [163], positively charged polyethyleneimine (PEI) was cross-linked to a poly(amide-imide) (PAI) hollow-fiber support, followed by deposition of a negatively-charged polystyrene sulfonate sodium salt. This one-bilayer PE membrane showed a water flux of $14 \pm 0.3$ $\mathrm{L} \cdot \mathrm{m}^{-2} \cdot \mathrm{h}^{-1}$ and a reverse salt flux ratio $\left(\mathrm{J}_{\mathrm{s}} / \mathrm{J}_{\mathrm{W}}\right)$ of $0.3\left(\mathrm{~g} \cdot \mathrm{L}^{-1}\right)$ in $\mathrm{FO}$, in which deionized water was utilized as the feed solution and $0.5 \mathrm{M} \mathrm{Na}_{2} \mathrm{SO}_{4}$ as draw solution. Here too, a slightly larger draw solute was chosen, relative to $\mathrm{NaCl}$. In a more recent study [164], two bilayers of PEI and poly (acrylic acid) (PAA) were deposited onto a polydopamine-functionalized polysulfone support. The FO performance of the membrane was tested with $0.5 \mathrm{M}$ trisodium citrate as draw solution; a high water flux of $22 \mathrm{~L} \cdot \mathrm{m}^{-2} \cdot \mathrm{h}^{-1}$ and a reasonable reverse salt flux of $0.06 \mathrm{~mol} \cdot \mathrm{m}^{-2} \cdot \mathrm{h}^{-1}$ were achieved. 
Overall, LbL may result in fewer defects in the selective layer especially for hollow fiber membranes. However, the current LbL-based layers are not yet suitable for $\mathrm{FO}$ applications when $\mathrm{NaCl}$ is used as draw solute. Therefore, more emphasis should be put on making these layers more selective. Alternatively, the focus should lie on using LbL-based membranes with larger solutes as draw solutions, which also opens up opportunities for more facile draw solute recovery schemes.

\section{Other Preparation Methods}

Asymmetric membranes by surface cross-linking. One of the methods to fabricate asymmetric membranes is via cross-linking the support's surface. In one study [107], polyamide-imide (PAI, Torlon) flat-sheet FO membranes were fabricated by phase inversion. The support's surface was then cross-linked to polyethyleneimine (PEI) to form the asymmetric membrane. The resulting membrane achieved a water flux of $19.2 \mathrm{~L} \cdot \mathrm{m}^{-2} \cdot \mathrm{h}^{-1}$ and $\left(\mathrm{J}_{\mathrm{s}} / \mathrm{J}_{\mathrm{w}}\right)$ ratio of $<0.5 \mathrm{~g} \cdot \mathrm{L}^{-1}$ in FO. To improve the adhesion of the selective layer to the support, Tashvigh and Chung [165] cross-linked the monomer dibromo-p-xylene to the surface of a polybenzimidazole (PBI) membrane, followed by exposing the cross-linked surface to PEI to form an ultra-thin selective layer. This membrane, however, showed a molecular weight cut-off of $\sim 350 \mathrm{Da}$, which makes it only suitable for FO when using draw solutes with a larger diameter than the pores.

Asymmetric membranes by surface blending. It is a common practice to improve the separation characteristics of polymeric membranes by adding materials that confer different physical and chemical properties to the membrane. Typically, an inorganic material is blended into the polymeric matrix. $\mathrm{TiO}_{2}$ nanoparticles, carbon nanotubes (CNTs), zeolite nanoparticles and graphene oxide (GO) nanosheets have been tried for FO membranes, with promising results [166-170]. Blending in nanoparticles improves water flux, rejection, hydrophilicity, mechanical stability and antifouling behavior [171,172].

Asymmetric membranes by surface grafting. In this method, inorganic nanoparticles or organic functional groups are grafted onto the surface of membranes by various methods such as plasma discharge, UV irradiation and ozone [173]. Unlike blending, surface grafting (chemical bonding) causes more integration into the structure of the polymer. As these nanoparticles cannot be easily separated from the membrane, grafting is preferred over blending because of the resulting greater nanocomposite membrane stability. Zhang et al. [55] prepared an enhanced anti-fouling FO membrane by surface grafting the polyamide selective layer with amine-terminated sulfonated poly (arylene ether sulfone). The same anti-fouling behavior was observed after surface-grafting of a zwitterionic monomer onto the selective layer of the FO membrane [174]. Finally, GO nanosheets have been successfully grafted onto the polyamide selective layer of a TFC membrane [175]; the resulting FO membrane showed a high salt rejection, a smooth surface, sufficient hydrophilicity, and a low biofouling tendency.

Integrally asymmetric membranes. An alternative method to fabricate a suitable FO membrane is via a conventional phase separation method which produces an asymmetric membrane. For hollow fiber (HF) fabrication, this method is shown to make the resulting membrane more robust as the selective top layer and support layer are formed simultaneously during spinning [176]. Yang et al. [177] pioneered HF membranes for FO by spinning a dual layer composite membrane containing PES/PVP as the support and polybenzimidazole (PBI) as the selective layer.

On the other hand, the following HF membranes fabricated with this method need further selectivity improvements to become potential candidates for next-generation FO membranes, certainly when using $\mathrm{NaCl}$ as draw solution. In one case, PEI was used in the bore liquid as cross-linker to the P84 polyimide which was used in the dope solution [178]. The resulting membranes from this simultaneous spinning/cross-linking process had a molecular weight cut-off in the range of 2.5-3.5 kDa, which means that further improvements are needed before they can be suitable for FO applications, though the reproducibility and simplicity of this one-step method are advantageous. Another simultaneous (single-step) method for forming a dense selective layer was developed by Gherasim et al. [179], who managed to form a polyelectrolyte-complex layer in the lumen part of hollow fibers by using a polyanion in the dope and a polycation in the bore liquid. The resulting fibers had a cut-off in the 
range of that of nanofiltration membranes [179]. This needs to be improved before they can become suitable for FO, but in this case too, the reproducibility and ease of this method are advantages.

Conclusions. Alternatives approaches to form a selective layer, such as the LbL method, could overcome the irreproducibility of IP method especially for hollow fibers supports. However, these layers need to be more selective especially towards low-molecular-weight/small draw salts. Integrally asymmetric membrane fabrication appears to be another interesting alternative as it could avoid all the difficulties associated with post-coating, be more time-efficient though not yet as selective as IP. Despite interesting results achieved with alternative coating methods, IP still remains the dominant method for preparing FO membranes in view of its high selectivity towards all types of solutes including smaller ones such as $\mathrm{NaCl}$.

\subsubsection{Support}

The membrane support usually is fabricated by a phase inversion process in which a dissolved polymer is transformed from a liquid (dissolved) to a solid state. In most cases, the phase inversion occurs by using an immersion precipitation process. The polymer solution is immersed in a coagulation bath containing a non-solvent for the polymer. The precipitation takes place due to solvent and non-solvent exchange. There are other less common precipitation techniques such as solvent evaporation, thermal precipitation, precipitation from the vapor phase and precipitation by controlled evaporation. The structure of the final membrane can be determined with the combination of mass transfer and phase separation thermodynamics [180]. Several parameters affect the membrane structure such as the choice of polymer/solvent/non-solvent, the composition of the polymer solution and coagulation bath, and the temperature of the polymer solution and the coagulation bath [180].

The polymer solvent plays a vital role in determining the final membrane properties. A good solvent leads to a uniformly distributed polymer configuration resulting in fewer defects in the membrane structure such as pinholes or even cracks [181]. In addition, the kinetics and thermodynamics of the phase separation are dependent on the non-solvent influx and solvent outflux. Thus, choosing a different solvent with different properties leads to different phase separation process. For example, if a solvent has slower outflux than the non-solvent influx, rapid demixing occurs which is the cause of large voids in the structure [137].

As mentioned, in FO membranes both the selective layers as well as the support are key players determining membrane performance. Typically, the top layer accounts for the salt rejection, while the support dominates the water flux (in case of water permeance of $\mathrm{A}>1\left(\mathrm{~L} \mathrm{~m}^{-2} \mathrm{~h}^{-1} \mathrm{bar}^{-1}\right)$ ). This is different from reverse osmosis (RO) and nanofiltration (NF) membranes in which the water transport resistance is predominantly determined by the selective layer. For FO the water transport becomes limited in the porous support due to internal concentration polarization (ICP) [182,183]. In contrast to pressure driven processes, the FO membrane support does not need to have a high mechanical strength since the hydraulic pressure produced by flowing pumps in the FO process is relatively low. In fact, using a very dense support designed for RO impedes mass transfer in the membrane and causes more severe ICP. Still, the mechanical strength of the membrane should not be so low that it is not able to handle industrial-scale FO operation [19], and arguably mechanical strength comparable to ultrafiltration membranes should suffice. Lastly, the support should exhibit a defect-free (free of pinholes) surface for the successful coating of the selective layer.

\section{Internal Concentration Polarization}

Concentration polarization $(\mathrm{CP})$ occurs in both pressure-driven and osmosis-driven membrane processes. However, it is more prominent in osmotically-driven membrane desalination processes such as FO due to the nature of the process [76,184]. Depending on whether the selective layer faces the draw solution (SL-DS) or the feed solution (SL-FS), CP is either concentrative or dilutive, respectively. Both concentrative and dilutive $\mathrm{CP}$ can happen within the support, referred to as internal concentration polarization (ICP) and at the membrane boundary, called external concentration 
polarization (ECP) [185]. In contrast, for pressure driven membranes processes, only ECP near the selective layer needs to be considered.

Thus, in FO mode (SL-FS orientation), the porous support layer prevents good mixing of the draw solution and the permeate in the membrane support, slowing down the mass transfer rate. As a result, less draw solute reaches the selective layer which causes a decrease in the driving force [14]. This is referred to as dilutive ICP because it occurs in the support. On the feed side, the water flow pushes solute from the feed solution towards the surface of the selective layer, which results in concentrative ECP (Figure 6a).
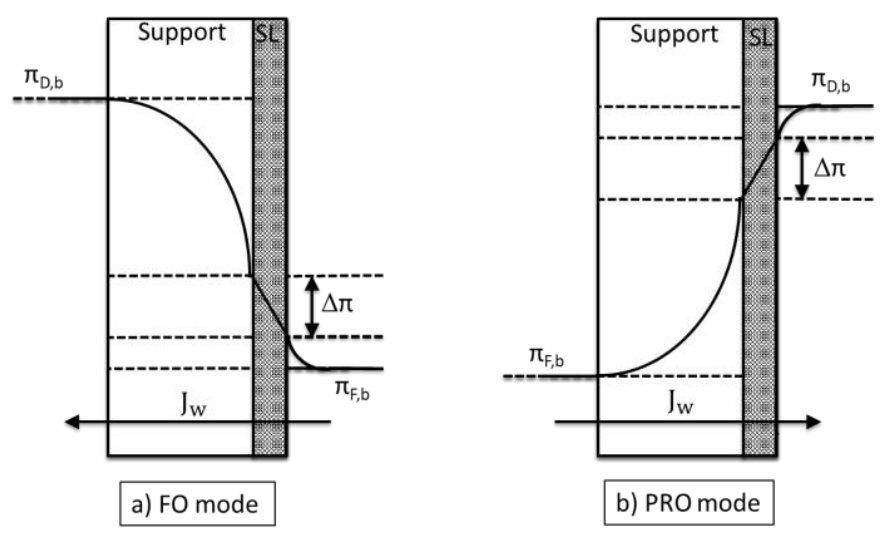

Figure 6. The orientation of support and selective layer (SL) in (a) FO mode (SL-FS), and (b) PRO mode. (SL-DS).

Similarly, PRO mode (SL-DS orientation) suffers from dilutive ECP and concentrative ICP. Concentrative ICP is due to two phenomena:

i. The convective flow pushes the feed solute into the support.

ii. The draw solute diffuses across the selective layer towards the feed solution $[76,186,187]$.

At the same time, the water flux pushes the draw solute away from the membrane surface, which leads to dilutive ECP (Figure 6 b).

Both concentrative and dilutive ICP lead to a dramatic drop in the osmotic pressure gradient across the selective layer and, consequently, to a lower water flux $[73,84,183,188]$. ICP has a far greater influence on the osmotic pressure gradient than ECP [185]. In addition, ECP can be easily diminished by increasing the cross-flow velocity, the addition of spacers, or using air bubbles. This leads to an increase in mixing near the membrane surface area, which reduces the ECP at the membrane surface [189]. Also, as in $\mathrm{RO}$, the FO permeate water flux is responsible for ECP, so by running the FO process at lower water fluxes (using a diluted draw solution), ECP becomes less significant $[185,190]$, however these lower water fluxes are typically undesirable. Both ICP and ECP can be minimized by increasing the temperature as it will increase the diffusion coefficient of draw solutes in water, leading to faster mixing and consequently to less ECP and ICP [76]. However, increasing the operating temperature increases the need for externally supplied energy which counteracts the electricity-friendly nature of the FO process. The impact of ICP on the FO water flux can be very severe, in some cases even leading to a water flux decrease of over $80 \%[136,182,185,191]$.

\section{Structural Parameter (S)}

The structural parameter of a membrane is described as an effective thickness of the membrane support, independent on operating conditions. A support with a lower S value experiences lower 
ICP and offers better FO performance with respect to water flux. Most researchers use the following semi-empirical method to determine the $S$ parameter (in $\mathrm{m}$ ) [182,183]:

$$
\mathrm{S}=\frac{\mathrm{D}}{\mathrm{J}_{\mathrm{w}}} \ln \frac{\mathrm{B}+\mathrm{A} \pi_{\mathrm{D}, \mathrm{b}}}{\mathrm{B}+\mathrm{J}_{\mathrm{w}}+\mathrm{A} \pi_{\mathrm{F}, \mathrm{m}}}
$$

In this equation, which is used for FO mode operation, $\mathrm{A}$ is the water permeance $\left(\mathrm{L} \mathrm{m}^{-2} \mathrm{~h}^{-1}\right.$ $\left.\operatorname{bar}^{-1}\right), \pi$ is the osmotic pressure (bar), and D is the solute diffusion coefficient $\left(\mathrm{m}^{2} \mathrm{~h}^{-1}\right)$. The water flux $J_{W}\left(\mathrm{~L} \mathrm{~m}^{-2} \mathrm{~h}^{-1}\right)$ is determined in an FO experiment and $\mathrm{B}$, the salt permeation constant $\left(\mathrm{L} \mathrm{m}^{-2}\right.$ $\mathrm{h}^{-1}$ ), is determined with a low-pressure RO experiment. For determining $\mathrm{B}$ the following equation is typically used:

$$
\mathrm{B}=\mathrm{J}_{\mathrm{W}}\left(\frac{1-\mathrm{R}}{\mathrm{R}}\right) \exp \left(-\frac{\mathrm{J}_{\mathrm{W}}}{\mathrm{K}}\right)
$$

Where $\mathrm{R}$ is the rejection (-) and $\mathrm{k}$ is the mass transfer coefficient for the corresponding membrane geometry and operating conditions. In some cases, a simplified version is used for determining $\mathrm{B}$, that does not take into account the concentration polarization in RO mode. Equation (2) then simplifies to:

$$
\mathrm{R}=\frac{\mathrm{J}_{\mathrm{w}}}{\mathrm{J}_{\mathrm{w}}+\mathrm{B}}
$$

Although Equation (1) should capture all different support properties that influence ICP, there are several disadvantages to solely using Equation (1) for characterizing the support. Measuring the water permeation (A) and salt permeation (B) of an $\mathrm{FO}$ membrane under $\mathrm{RO}$ conditions and assuming them to be equal to the values in $\mathrm{FO}$ mode is the first drawback of this approach. The selective layer properties (A and $\mathrm{B}$ ) in $\mathrm{RO}$ are different than in $\mathrm{FO}$, as the mechanism behind pressure-driven (RO) and osmosis driven (FO) processes is different [192]. As the B value can be dependent on the solute concentration [193], a highly concentrated process like FO may present a larger B-value than a low concentration process ( $\mathrm{RO}$ ). The presence of the highly concentrated draw solution leads to a lower Donnan potential and greater driving force in FO, relative to RO. Measuring B values at higher ionic strength is typically not done, probably due to the high operating pressures needed to overcome the osmotic pressures. Tiraferri et al. [192] developed a new method to predict the water and salt fluxes (A and B) more accurately by using a single FO experiment. They changed the draw solution three times during the FO experiment and measured the water flux $\left(\mathrm{J}_{\mathrm{W}}\right)$ and reverse salt flux $\left(\mathrm{J}_{\mathrm{S}}\right)$ in each of these four stages. In their study, A, B, and S were used as adjustable parameters to fit the FO transport equations to the experimental $\mathrm{J}_{\mathrm{W}}$ and $\mathrm{J}_{\mathrm{s}}$. Different $\mathrm{A}$ and $\mathrm{B}$ values were found when the conventional approach (based on the low-pressure RO experiment) was taken than when they used their newly developed method (based on FO experiments), even though the same membranes were used. For all tested TFC membranes, a considerably lower A/B ratio (30\% to $50 \%$ lower) was found when they used their new method for FO relative to the method for RO [192].

Secondly, this obtained S value is partially dependent on the experimental conditions rather than only on the support's structural characteristics. This already was shown in Figure 4. Since there are no standardized FO and RO experimental test conditions for measuring $\mathrm{S}$, the accuracy of the estimated $\mathrm{S}$ would be affected by any differences in experimental conditions and implementations [23]. Therefore, measuring the $\mathrm{S}$ of a single support but at different test conditions will lead to different values. This was confirmed by Cath et al. [194], who tested the FO performance of two FO membranes (TFC and asymmetric) at seven different laboratories and the determined $\mathrm{S}$ was around $350 \mu \mathrm{m}$ with a deviation of $150 \mu \mathrm{m}$ and nearly $500 \mu \mathrm{m}$ with a deviation of $200 \mu \mathrm{m}$ for TFC and asymmetric membranes, respectively. In another study [151], the S parameter of an aquaporin-inside flat sheet membrane was measured at different draw solution concentration conditions. The concentration of the $\mathrm{NaCl}$ draw solution ranged from $0.1 \mathrm{M}$ to $1.5 \mathrm{M}$ which led to a change in $\mathrm{S}$ from $680 \mu \mathrm{m}$ to 444 $\mu \mathrm{m}$ [151]. Furthermore, Bui et al. [113] presented a model to accurately calculate the $S$ parameter by encapsulation of all significant boundary layer phenomena which are typically neglected by other 
models. However, this method also resulted in different $S$ parameters for a support tested at different cross-flow velocities. It is thus important to note that the performance of one support compared another or even the suitability of a single support cannot be solely identified by the $S$ value (Equation (1)), unless carried out under exactly identical experimental conditions.

Thirdly, the approach based on Equation (1) only considers the transport resistance in the entire membrane and does not make a distinction between resistance occurring in the individual support and resistance in the selective layer. In order to measure $S$, the support first must be coated with a selective layer, which is usually done by applying the IP technique. However, depositing a coating using IP is laborious and not easily reproducible (Section 2.2.1), which perhaps surprisingly affects the value of the calculated S. Chi et al. [195] obtained different S values for the same support when they changed the ethanol concentration in the aqueous MPD phase for IP-coating. Increasing the ethanol concentration from $25 \mathrm{wt} . \%$ to $100 \mathrm{wt}$ \% led to a decrease in the S value from $463 \mu \mathrm{m}$ to $350 \mu \mathrm{m}$ [195]. This study highlights an unanticipated sensitivity of the outcome of Equation (1) with respect to the selective layer, even though this in principle should only be affected by the support.

Alternatively, the structural parameter can be determined via the intrinsic properties of a support. This intrinsic structural parameter, $S_{\text {int }}$, is defined as follows [196]:

$$
\mathrm{S}_{\mathrm{int}}=\frac{1 \tau}{\varepsilon}
$$

Here, 1 is the thickness $(m), \tau$ is the tortuosity $(-)$, and $\varepsilon$ is the porosity $(-)$ of the support layer. The $S$ parameter basically is an indication of the effective diffusion pathlength that a solute must travel through the membrane support layer until it reaches the selective layer. Generally, a shorter diffusion distance makes it easier for the solute to penetrate and mix, which results in less ICP. There have been extensive studies on the development of suitable membrane structures for FO-i.e., with a low $S$ parameter-in the past decades [14]. However, there are also limitations to predicting ICP by using Equation (4) to calculate $S_{\text {int }}$ and correlating it to FO performance. Firstly, while the thickness of a support can be determined easily by microscopy techniques, it is far more challenging to measure its porosity and hardly possible to measure its tortuosity. Even more so, as asymmetry in the porosity and tortuosity are never accounted for. Secondly, several other parameters besides tortuosity, porosity, and thickness are known to influence ICP, i.e. the support pore diameter [114,197], pore morphology [136,198-200], hydrophilicity [187,195,201], and charge [202].

Pore diameter. In addition to the direct contribution of larger pores to the porosity which results in a lower $S$ parameter, they also affect the interfacial polymerization process. Changing the pore dimensions results in a different polyamide morphology, degree of cross-linking, and layer thickness while all these factors in the selective layer influence the $S$ value as well. Huang et al. [197] studied the influence of support pore size on FO performance. They tested four different supports with a pore size range between 0.025 and $0.45 \mu \mathrm{m}$, and the support with the largest pores showed the lowest $S$ parameter of $1400 \pm 160 \mu \mathrm{m}$ [197]. A similar effect was observed by Ren et al. [114] who found that the roughness of the selective layer depends on the support's pore size. Larger pores result in a rougher selective layer which results in a higher flux [114].

Morphology. Yip et al. [136] demonstrated that the combination of a finger- and a sponge-like structure is optimal for FO supports as it results in the greatest osmotic water flux. They attributed the higher water flux of this combination as compared to commercially available membranes to its thickness, porosity, tortuosity, and pore structure [136]. After IP coating, this support showed a lower $S$ parameter of $492 \pm 38 \mu \mathrm{m}$, which is considerably lower than the $\mathrm{S}$ parameter of two commercially available membranes; the $S$ was $595 \pm 114 \mu \mathrm{m}$ for commercial asymmetric cellulose triacetate (HTI-CTA) FO membrane (Hydration Technology Inc., Albany, OR) and it was $9583 \pm 1351 \mu \mathrm{m}$ for commercial RO membrane (TFC-RO, SW30-HR, Dow Chemical Company, Midland, MI). However, Yip et al. did not investigate other properties of the three supports that might affect ICP. In another study [199], different membrane supports were prepared by varying the polymer-solvent ratio. These membranes differed in 
structure morphology, pore size, and thickness. A thin sponge-like layer sitting on top of a finger-like morphology was found to possess the lowest $S$ parameter $(312 \pm 72 \mu \mathrm{m})$. The better performance of the finger-like pore structure over the spongy structure in minimizing ICP has been demonstrated by Wei et al. as well [200]. A contrary result was achieved in a study by Widjojo et al. [198], in which the sponge-like structure of the support showed a lower S parameter $(324 \mu \mathrm{m})$ than its finger-structured counterparts $(338 \mu \mathrm{m}$ and $636 \mu \mathrm{m})$. The better performance of the sponge-like support was in this specific case attributed to its higher hydrophilicity.

It seems clear that there is still considerable uncertainty about the optimal support morphology for FO applications. In Table 1, an overview of different hollow fiber membrane results is given that have been published recently, sorted by S parameter. Although correlations between membrane permeance, structural parameter and obtained $\mathrm{FO}$ water flux are apparent (also see Figure 4), there seems no correlation between the S parameter obtained from FO experiments (via Equation (1)) and the support geometry. This becomes even more evident when correcting for the thickness of the support by dividing $S$ with 1 , negating any variations in thicknesses. The obtained value is the effective correction factor for the support thickness due to the longer diffusive path length within the support. For all the sponge-like membranes the mean of $S / 1$ is $4.2 \pm 2.5$ and for the finger-like membrane the mean is $3.1 \pm 1.5$. Although for the finger-like morphology the average is somewhat lower, the difference is by no means significant. This is supported by the result of a simple two-tailed t-test assuming equal variances. For this test, with a significance level of 0.05 , the $t_{\text {crit }}$ is 2.06 while the statistical $t$ value is 1.36. This means that the null hypothesis cannot be rejected, or in other words there is no statistical evidence that the mean of the $S / l$ for the finger-like membranes is significantly different compared to the mean of the sponge-like membranes.

Table 1. Overview of hollow fiber FO membrane results published recently (data arranged based on S from low to high).

\begin{tabular}{|c|c|c|c|c|c|c|c|}
\hline $\begin{array}{c}A \\
\left(\mathrm{~L} \mathrm{~m}^{-2} \mathrm{~h}^{-1} \mathrm{bar}^{-1}\right)\end{array}$ & $\begin{array}{c}\mathrm{J}_{\mathrm{W}} \\
\left(\mathrm{L} \mathrm{m}^{-2} \mathrm{~h}^{-1}\right)\end{array}$ & $\begin{array}{c}\mathrm{S} \\
(\mu \mathrm{m})\end{array}$ & $\begin{array}{c}B \\
\left(\mathrm{~L} \mathrm{~m}^{-2} \mathrm{~h}^{-1}\right)\end{array}$ & $\begin{array}{c}\text { Draw } \\
(\mathrm{M} \mathrm{NaCl})\end{array}$ & Morphology & S/1 (-) & Reference \\
\hline 2.37 & 25 & 183 & 0.11 & 0.5 & sponge & 1.4 & [203] \\
\hline 2.26 & 30 & 190 & 0.28 & 1 & finger & 2.9 & [127] \\
\hline 2.11 & 23 & 202 & 0.05 & 0.5 & sponge & 1.6 & [203] \\
\hline 0.43 & 13 & 210 & 0.05 & 1 & sponge & 2.6 & [125] \\
\hline 1.68 & 25 & 214 & 0.30 & 1 & finger & 3.5 & [127] \\
\hline 1.22 & 22 & 232 & 0.05 & 1 & sponge & 2.3 & [128] \\
\hline 3.44 & 32 & 254 & 0.40 & 1 & finger & 1.8 & [121] \\
\hline 2.20 & 24 & 305 & 1.50 & 1 & finger & 6.1 & [130] \\
\hline 2.85 & 25 & 308 & 0.36 & 1 & finger & 2.1 & [121] \\
\hline 1.80 & 15 & 335 & n.a. & 0.5 & finger & 2.2 & [204] \\
\hline 2.02 & 16 & 377 & 0.06 & 0.5 & sponge & 2.9 & [203] \\
\hline 2.45 & 20 & 428 & 0.77 & 1 & finger & 5.5 & [127] \\
\hline 2.60 & 23 & 446 & 0.12 & 1 & finger & 2.5 & [119] \\
\hline 0.71 & 12 & 472 & 0.02 & 1 & finger & 2.6 & [128] \\
\hline 1.90 & 18 & 499 & 0.75 & 1 & finger & 5.0 & [130] \\
\hline 2.00 & 17 & 549 & 0.70 & 1 & finger & 5.5 & [130] \\
\hline 2.80 & 20 & 595 & 0.17 & 1 & finger & 3.3 & [120] \\
\hline 0.32 & 8 & 674 & 0.20 & 1 & finger & 1.7 & [114] \\
\hline 3.03 & 16 & 710 & 1.76 & 1 & sponge & 8.9 & [122] \\
\hline 0.30 & 7 & 715 & 0.10 & 1 & finger & 1.8 & [114] \\
\hline 0.41 & 10 & 725 & 0.30 & 1 & finger & 1.8 & [114] \\
\hline 0.42 & 10 & 725 & 0.02 & 1 & finger & 1.8 & [114] \\
\hline 0.33 & 6 & 827 & 0.70 & 1 & finger & 2.1 & [114] \\
\hline 1.40 & 9 & 1110 & 0.18 & 1 & sponge & 4.4 & [129] \\
\hline 2.20 & 11 & 1252 & n.a. & 1 & sponge & 6.3 & [118] \\
\hline 2.26 & 10 & 1403 & n.a. & 1 & sponge & 7.0 & [118] \\
\hline
\end{tabular}

Hydrophilicity. Hydrophilicity is one of the parameters of which the influence on FO performance has been extensively investigated. Not only does the hydrophilicity of the membrane support assist in wetting and water continuity within the membrane, it also mitigates ICP [187]. Widjojo et al. [198] 
showed that the support's hydrophilicity had a greater impact on FO performance than morphology. They managed to fabricate supports with different morphologies and degrees of hydrophilicity by changing the amount of sulfonated material in the membrane support. Interestingly, the sponge-like more hydrophilic structure produced the best results in FO [198]. However, a better explanation for the superior performance of the support with more sulfonated material could be its charge. The higher surface charge facilitates diffusion of the draw solutes in the support, resulting in less ICP and consequently better FO performance. In another approach, two commercially available TFC RO membranes were coated with polydopamine (PDA) to increase their hydrophilicity [201]. This led to a significant improvement in flux in PRO mode. It was claimed that the coated hydrophilic layer promotes the complete wetting of the pore structure, which is referred to by the term "wetted porosity". The "wetted porosity" is the reason for the increase in water transport through the support layer, as well as for the decrease in ICP. The reason for the ICP reduction is that the wetted porosity facilitates the diffusion of the leaked draw solute out of the membrane support [201].

Charge. Surface-charged polystyrene particles were blended into polysulfone FO supports in a study by Zuo et al. [202]. The incorporation of the particles not only led to increased hydrophilicity and porosity but also resulted in a significant internal osmotic pressure (IOP) of the support layer. Consequently, the structural parameter improved remarkably, from 1550 to $670 \mu \mathrm{m}$ [202]. According to other research [205], ionic polymer networks show a considerably higher IOP relative to non-ionic ones as a result of the presence of the charges and the translational degree of freedom of counterions in the polymer networks. In FO mode, the draw counterions get stuck in the charged support network, supposedly resulting in an increase in the internal osmotic pressure, which boosts the effective driving force [205]. However, the fact that these ions become fixed in the polymer network negates the assumption of their contribution towards the osmotic pressure. This is because only an ion existing in a liquid can contribute to the ion concentration and hence to the osmotic pressure. Therefore, the decrease in the $S$ parameter could actually be due to the increased draw solute diffusion inside the support as a result of the charged surface. The charged surface leads to a smaller Debye length in the pores resulting in less friction between the solutes and the pores' surface.

In addition, Equation (4) uses the bulk properties of the support (bulk porosity and tortuosity). However, in asymmetric structures, the porosity and tortuosity change along the structure. Therefore, using the average porosity and tortuosity values does not reveal how this asymmetry influences the mass transfer [23].

By comparing the shortcomings attributed to each of the Equations (1) and (4), the latter may give a fairer estimation of ICP as it uses actual FO and RO based data and is not solely limited to intrinsic parameters. However, it generates inaccurate and/or irreproducible $S$ values when it is used to compare different membranes and even when the same membrane is examined under different experiment conditions $[23,186,194,206]$. Put differently, Equation (1) does not yield a good indicator for assessing ICP $[23,24,195]$. For better estimations of ICP (hence of membrane performance), it is essential to develop a reliable, standardized method for determining $S$ that incorporates all parameters that influence $S$.

Impact of Wall Thickness on S Relative to The Influence of Tortuosity and Porosity

It has been argued that of the three support's main intrinsic properties wall thickness, porosity, and tortuosity, the wall thickness is the major factor to be considered [207]. Several researchers have observed that a thinner support layer results in a significant reduction in ICP and consequently a greater FO water flux $[73,187,208]$. This is mostly due to the fact that porosity and tortuosity can only change within a limited range; their influence on the S parameter is therefore less significant. Krull et al. [209] carried out an extensive literature review of porous supports for liquid membranes used in gas/vapor separations. The porosities of these supports lie between 0.4 and 0.83 , the tortuosities are between 1 and 3.05 and the thicknesses range from 25 to $380 \mu \mathrm{m}$ [209]. 
We decided to expand on that study to investigate the potential effects of tortuosity, porosity and thickness in FO membranes with regard to ICP. We first extracted the porosity and tortuosity data for several porous media used as membrane support from various sources (Figure 7). As with S, different approaches have been taken to determine the tortuosity as there is no universal approach yet for measuring tortuosity in porous media. In some of the studies [191,210], tortuosity was measured based on the assumption that the Equations (1) and (4) result in identical S values. In this approach, S is determined first from Equation (1) and the tortuosity is then calculated with Equation (5), using the porosity and wall thickness of the support.

$$
\tau=\frac{\mathrm{S} \varepsilon}{1}
$$

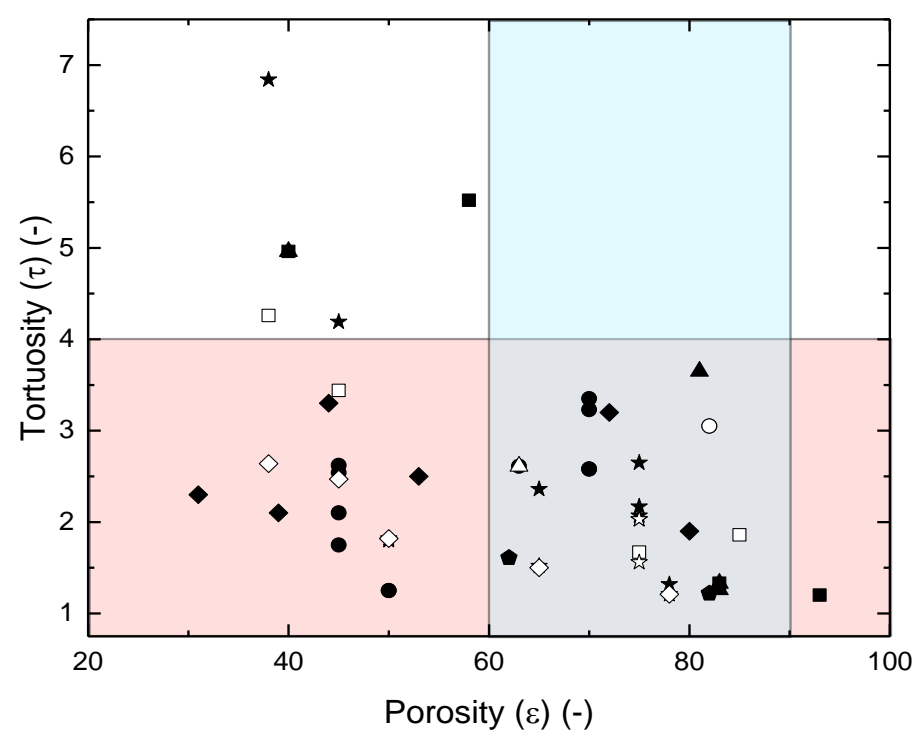

Figure 7. The porosity and tortuosity gathered from literature. (Filled black square (घ) [191], Filled black circle $(\bullet)$ [209], Filled black triangle $(\boldsymbol{\Delta})$ [210], Filled lozenge ( $\bullet$ ) [211], Filled black star $(\star)$ [212], Filled black pentagon $(\bullet)$ [213], Empty square (口) [214], Empty circle (○) [215] , Empty triangle [216] $(\Delta)$, Empty lozenge $(\diamond)$ [217], Empty star (炎) [218]).

It is worth noting that the obtained tortuosity is obviously a mere indication since, as explained in Section 2.2.2 Equations (1) and (4) do not result in the same value of S.

In some of the studies presented in Figure 7, despite the high porosity of the porous media, a high value was determined for the tortuosity which seems unrealistic in view of the relation between porosity and tortuosity: In principle, increasing the porosity leads to a decrease in tortuosity due to the more open structure; this relation can be derived from work in other fields, such as hydrology, in which tortuosity measurement is a more mature art [219] and it is evident that with increasing porosity, the tortuosity decreases [220]. In the work of Boving et al. [220], the experimentally measured tortuosity of limestone rocks dropped to below 3 for porosities above $40 \%$. A soil science review on tortuosity in porous media [221] found that in almost all approaches, a porosity above $80 \%$ corresponds to a tortuosity of close to unity.

To study the impact of the wall thickness on ICP (S parameter), we need to settle a boundary for tortuosity and porosity of the supports typically used for FO membranes. Considering the typical porosities of $60-90 \%$ used for FO supports, corresponding tortuosities found in the literature are between 1 to 4 (as marked in Figure 7). In addition, we consider the thickness of the support to be between 20 and $200 \mu \mathrm{m}$ as a support thinner than $20 \mu \mathrm{m}$ would suffer from low mechanical stability and supports with a thickness above $200 \mu \mathrm{m}$ are unnecessarily thick (and hardly reported). Assuming that all the other factors remain constant, we calculated the sensitivity of $S_{\text {int }}$ with Equation (4) for 
different ranges of the tortuosity, porosity, and wall thickness. The results are that the porosity can only influence $S_{\text {int }}$ with a factor of 1.5 and the tortuosity with a factor of 4 , while the sensitivity to the thickness is up to a factor of 10. It must be noted that, for simplicity, we disregard any effects of stirring within the support that would in fact decrease the calculated S parameter as well [113].

Based on this simple sensitivity analysis it is fair to say that although it is essential to fabricate highly porous and less tortuous supports, most attention should be allocated to decreasing the wall thickness when designing supports for FO membranes.

\section{Concluding Remarks}

The FO process shows great potential in applications such as wastewater treatment, seawater desalination, dewatering and concentration, and removal of various solutes. However, FO still suffers from low water fluxes, which puts it at a disadvantage relative to other processes such as RO. To increase the water flux, better membrane supports are needed that have less ICP. This is even more relevant for the many promising applications where the hollow fiber geometry is preferred. In addition to the support and the selective layers, the draw solute diffusivity can also affect the ICP as a highly diffusive draw solute decreases the ICP. The ICP can be determined intrinsically and empirically, and each of these approaches has its shortcomings. More work is needed to find an accurate method and a universal testing condition to estimate the ICP. Only this will allow a proper development of the next generation of supports for FO membranes.

Tortuosity and porosity of the support generally have less effect on the structural factor than its thickness. We found no statistical evidence from literature data that a certain type of morphology results in better FO performance. One of the main parameters that can help in reducing ICP is the support's thickness. In this paper, we have shown that the wall thickness of the support can impact the structural factor $\mathrm{S}$ by a factor of 10 . Thus, a greater effort should therefore go into developing polymer recipes for thinner supports that still have sufficient mechanical strength.

Author Contributions: M.M. conducted the literature review and wrote the manuscript; J.d.G. and A.J.B.K. contributed to the concept and reviewed the manuscript; J.d.G. and H.D.W.R. checked the final document. All authors have read and agreed to the published version of the manuscript.

Funding: This work was made possible by financial support from Aquaporin A/S in Denmark and the TKI HTSM: University of Twente impulse program in The Netherlands, for which the authors are very grateful.

Conflicts of Interest: The authors declare no conflict of interest. The funders had no role in the design of the study; in the collection, analyses, or interpretation of data; in the writing of the manuscript, or in the decision to publish the results.

\section{References}

1. McGinnis, R.I.; Elimelech, M. Global Challenges in Energy and Water Supply: The Promise of Engineered Osmosis. Environ. Sci. Technol 2008, 42, 8625-8629. [CrossRef] [PubMed]

2. Shannon, M.A.; Bohn, P.W.; Elimelech, M.; Georgiadis, J.G.; Marĩas, B.J.; Mayes, A.M. Science and technology for water purification in the coming decades. Nature 2008, 452, 301-310. [CrossRef] [PubMed]

3. Elimelech, M.; Phillip, W.A. The Future of Seawater Desalination: Energy, Technology, and the Environment. Science 2011, 333, 712-717. [CrossRef] [PubMed]

4. Zhao, S.; Zou, L.; Tang, C.Y.; Mulcahy, D. Recent developments in forward osmosis: Opportunities and challenges. J. Membr. Sci. 2012, 396, 1-21. [CrossRef]

5. Nurizzo, C.; Antonelli, M.; Profaizer, M.; Romele, L. By-products in surface and reclaimed water disinfected with various agents. Desalination 2005, 176, 241-253. [CrossRef]

6. Cath, T.Y.; Hancock, N.T.; Lundin, C.D.; Hoppe-jones, C.; Drewes, J.E. A multi-barrier osmotic dilution process for simultaneous desalination and purification of impaired water. J. Membr. Sci. 2010, 362, 417-426. [CrossRef]

7. Fritzmann, C.; Löwenberg, J.; Wintgens, T.; Melin, T. State-of-the-art of reverse osmosis desalination. Desalination 2007, 216, 1-76. [CrossRef] 
8. Lee, K.P.; Arnot, T.C.; Mattia, D. A review of reverse osmosis membrane materials for desalination-Development to date and future potential. J. Membr. Sci. 2011, 370, 1-22. [CrossRef]

9. Lin, S.; Elimelech, M. Staged reverse osmosis operation: Configurations, energy efficiency, and application potential. Desalination 2015, 366, 9-14. [CrossRef]

10. Scott, C.A.; Pierce, S.A.; Pasqualetti, M.J.; Jones, A.L.; Montz, B.E.; Hoover, J.H. Policy and institutional dimensions of the water-energy nexus. Energy Policy 2011, 39, 6622-6630. [CrossRef]

11. King, C.W.; Webber, M.E. Water intensity of transportation. Environ. Sci. Technol. 2008, 42, 7866-7872. [CrossRef] [PubMed]

12. Nasr, P.; Sewilam, H. Forward osmosis: An alternative sustainable technology and potential applications in water industry. Clean Technol. Environ. Policy 2015, 17, 2079-2090. [CrossRef]

13. Lutchmiah, K.; Verliefde, A.R.D.; Roest, K.; Rietveld, L.C.; Cornelissen, E.R. Forward osmosis for application in wastewater treatment: A review. Water Res. 2014, 58, 179-197. [CrossRef]

14. Cath, T.Y.; Childress, A.E.; Elimelech, M. Forward osmosis: Principles, applications, and recent developments. J. Membr. Sci. 2006, 281, 70-87. [CrossRef]

15. Chung, T.-S.; Zhang, S.; Wang, K.Y.; Su, J.; Ling, M.M. Forward osmosis processes: Yesterday, today and tomorrow. Desalination 2012, 287, 78-81. [CrossRef]

16. Bajraktari, N.; Hélix-nielsen, C.; Madsen, H.T. Pressure retarded osmosis from hypersaline sources-A review. Desalination 2017, 413, 65-85. [CrossRef]

17. Shaffer, D.L.; Werber, J.R.; Jaramillo, H.; Lin, S.; Elimelech, M. Forward osmosis: Where are we now? Desalination 2015, 356, 271-284. [CrossRef]

18. Eyvaz, M.; Arslan, S.; İmer, D.; Yuksel, E.; Koyuncu, I. Forward Osmosis Membranes-A Review: Part I; IntechOpen: London, UK, 2018; ISBN 978-953-51-3921-8.

19. Wang, Y.; Goh, K.; Li, X.; Setiawan, L.; Wang, R. Membranes and processes for forward osmosis-based desalination: Recent advances and future prospects. Desalination 2018, 434, 81-99. [CrossRef]

20. Suwaileh, W.A.; Johnson, D.J.; Sarp, S.; Hilal, N. Advances in forward osmosis membranes: Altering the sub-layer structure via recent fabrication and chemical modification approaches. Desalination 2018, 436, 176-201. [CrossRef]

21. Lee, D.-J.; Hsieh, M.-H. Forward osmosis membrane processes for wastewater bioremediation: Research needs. Bioresour. Technol. 2019, 290, 121795. [CrossRef]

22. Chia, W.Y.; Khoo, K.S.; Chia, S.R.; Chew, K.W.; Yew, G.Y.; Ho, Y.-C.; Show, P.L.; Chen, W.-H. Factors Affecting the Performance of Membrane Osmotic Processes for Bioenergy Development. Energies 2020, $13,481$. [CrossRef]

23. Manickam, S.S.; McCutcheon, J.R. Understanding mass transfer through asymmetric membranes during forward osmosis: A historical perspective and critical review on measuring structural parameter with semi-empirical models and characterization approaches. Desalination 2017, 421, 110-126. [CrossRef]

24. Kim, B.; Gwak, G.; Hong, S. Review on methodology for determining forward osmosis (FO) membrane characteristics: Water permeability (A), solute permeability (B), and structural parameter (S). Desalination 2017, 422, 5-16. [CrossRef]

25. Ang, W.L.; Mohammad, A.W.; Johnson, D.; Hilal, N. Unlocking the application potential of forward osmosis through integrated/hybrid process. Sci. Total Environ. 2020, 706, 136047. [CrossRef] [PubMed]

26. Li, L.; Shi, W.; Yu, S. Research on Forward Osmosis Membrane Technology Still Needs Improvement in Water Recovery and Wastewater Treatment. Water 2019, 12, 107. [CrossRef]

27. Chaoui, I.; Abderafi, S.; Vaudreuil, S.; Bounahmidi, T. Water desalination by forward osmosis: Draw solutes and recovery methods-Review. Environ. Technol. Rev. 2019, 8, 25-46. [CrossRef]

28. Long, Q.; Jia, Y.; Li, J.; Yang, J.; Liu, F.; Zheng, J.; Yu, B. Recent Advance on Draw Solutes Development in Forward Osmosis. Processes 2018, 6, 165. [CrossRef]

29. Johnson, D.J.; Suwaileh, W.A.; Mohammed, A.W.; Hilal, N. Osmotic's potential: An overview of draw solutes for forward osmosis. Desalination 2018, 434, 100-120. [CrossRef]

30. Sreedhar, I.; Khaitan, S.; Gupta, R.; Reddy, B.M.; Venugopal, A. An odyssey of process and engineering trends in forward osmosis. Environ. Sci. Water Res. Technol. 2018, 4, 129-168. [CrossRef]

31. Dutta, S.; Nath, K. Prospect of ionic liquids and deep eutectic solvents as new generation draw solution in forward osmosis process. J. Water Process Eng. 2018, 21, 163-176. [CrossRef] 
32. Ansari, A.J.; Hai, F.I.; Price, W.E.; Drewes, J.E.; Nghiem, L.D. Forward osmosis as a platform for resource recovery from municipal wastewater-A critical assessment of the literature. J. Membr. Sci. 2017, 529, 195-206. [CrossRef]

33. Wibisono, Y.; Agung Nugroho, W.; Akbar Devianto, L.; Adi Sulianto, A.; Roil Bilad, M. Microalgae in Food-Energy-Water Nexus: A Review on Progress of Forward Osmosis Applications. Membranes 2019, 9, 166. [CrossRef] [PubMed]

34. Ang, W.L.; Wahab Mohammad, A.; Johnson, D.; Hilal, N. Forward osmosis research trends in desalination and wastewater treatment: A review of research trends over the past decade. J. Water Process Eng. 2019, 31, 100886. [CrossRef]

35. Goh, P.S.; Ismail, A.F.; Ng, B.C.; Abdullah, M.S. Recent Progresses of Forward Osmosis Membranes Formulation and Design for Wastewater Treatment. Water 2019, 11, 2043. [CrossRef]

36. Das, P.; Singh, K.K.K.; Dutta, S. Insight into emerging applications of forward osmosis systems. J. Ind. Eng. Chem. 2019, 72, 1-17. [CrossRef]

37. Ray, S.S.; Chen, S.-S.; Sangeetha, D.; Chang, H.-M.; Thanh, C.N.D.; Le, Q.H.; Ku, H.-M. Developments in forward osmosis and membrane distillation for desalination of waters. Environ. Chem. Lett. 2018, 16, 1247-1265. [CrossRef]

38. Haupt, A.; Lerch, A. Forward Osmosis Application in Manufacturing Industries: A Short Review. Membranes 2018, 8, 47. [CrossRef]

39. $\mathrm{Xu}, \mathrm{W}$.; Chen, Q.; Ge, Q. Recent advances in forward osmosis (FO) membrane: Chemical modifications on membranes for FO processes. Desalination 2017, 419, 101-116. [CrossRef]

40. Li, L.; Liu, X.; Li, H. A review of forward osmosis membrane fouling: Types, research methods and future prospects. Environ. Technol. Rev. 2017, 6, 26-46. [CrossRef]

41. Yadav, S.; Saleem, H.; Ibrar, I.; Naji, O.; Hawari, A.A.; Alanezi, A.A.; Zaidi, S.J.; Altaee, A.; Zhou, J. Recent developments in forward osmosis membranes using carbon-based nanomaterials. Desalination 2020, 482, 114375. [CrossRef]

42. Lee, W.J.; Ng, Z.C.; Hubadillah, S.K.; Goh, P.S.; Lau, W.J.; Othman, M.H.D.; Ismail, A.F.; Hilal, N. Fouling mitigation in forward osmosis and membrane distillation for desalination. Desalination 2020, 480, 114338. [CrossRef]

43. Firouzjaei, M.D.; Seyedpour, S.F.; Aktij, S.A.; Giagnorio, M.; Bazrafshan, N.; Mollahosseini, A.; Samadi, F.; Ahmadalipour, S.; Firouzjaei, F.D.; Esfahani, M.R.; et al. Recent advances in functionalized polymer membranes for biofouling control and mitigation in forward osmosis. J. Membr. Sci. 2020, 596, 117604. [CrossRef]

44. Ly, Q.V.; Hu, Y.; Li, J.; Cho, J.; Hur, J. Characteristics and influencing factors of organic fouling in forward osmosis operation for wastewater applications: A comprehensive review. Environ. Int. 2019, 129, 164-184. [CrossRef] [PubMed]

45. Ibrar, I.; Naji, O.; Sharif, A.; Malekizadeh, A.; Alhawari, A.; Alanezi, A.A.; Altaee, A. A Review of Fouling Mechanisms, Control Strategies and Real-Time Fouling Monitoring Techniques in Forward Osmosis. Water 2019, 11, 695. [CrossRef]

46. Chun, Y.; Mulcahy, D.; Zou, L.; Kim, I.S. A short review of membrane fouling in forward osmosis processes. Membranes 2017, 7, 1-23. [CrossRef] [PubMed]

47. Zou, S.; Qin, M.; He, Z. Tackle reverse solute flux in forward osmosis towards sustainable water recovery: Reduction and perspectives. Water Res. 2019, 149, 362-374. [CrossRef]

48. Alejo, T.; Arruebo, M.; Carcelen, V.; Monsalvo, V.M.; Sebastian, V. Advances in draw solutes for forward osmosis: Hybrid organic-inorganic nanoparticles and conventional solutes. Chem. Eng. J. 2017, 309, 738-752. [CrossRef]

49. Khan, J.A.; Shon, H.K.; Nghiem, L.D. From the Laboratory to Full-Scale Applications of Forward Osmosis: Research Challenges and Opportunities. Curr. Pollut. Rep. 2019, 5, 337-352. [CrossRef]

50. Awad, A.M.; Jalab, R.; Minier-Matar, J.; Adham, S.; Nasser, M.S.; Judd, S.J. The status of forward osmosis technology implementation. Desalination 2019, 461, 10-21. [CrossRef]

51. Kwan, S.E.; Bar-zeev, E.; Elimelech, M. Biofouling in forward osmosis and reverse osmosis: Measurements and mechanisms. J. Membr. Sci. 2015, 493, 703-708. [CrossRef]

52. Xie, M.; Lee, J.; Nghiem, L.D.; Elimelech, M. Role of pressure in organic fouling in forward osmosis and reverse osmosis. J. Membr. Sci. 2015, 493, 748-754. [CrossRef] 
53. Lotfi, F.; Chekli, L.; Phuntsho, S.; Hong, S.; Choi, J.Y.; Shon, H.K. Understanding the possible underlying mechanisms for low fouling tendency of the forward osmosis and pressure assisted osmosis processes. Desalination 2017, 421, 89-98. [CrossRef]

54. Yu, Y.; Lee, S.; Maeng, S.K. Forward osmosis membrane fouling and cleaning for wastewater reuse. J. Water Reuse Desalin. 2016, 7, 111-120. [CrossRef]

55. Zhang, X.; Tian, J.; Gao, S.; Zhang, Z.; Cui, F.; Tang, C.Y. In situ surface modification of thin film composite forward osmosis membranes with sulfonated poly (arylene ether sulfone) for anti-fouling in emulsified oil/water separation. J. Membr. Sci. 2017, 527, 26-34. [CrossRef]

56. Jin, L.; Wang, Z.; Zheng, S.; Mi, B. Polyamide-crosslinked graphene oxide membrane for forward osmosis. J. Membr. Sci. 2018, 545, 11-18. [CrossRef]

57. Mi, B.; Elimelech, M. Chemical and physical aspects of organic fouling of forward osmosis membranes. J. Membr. Sci. 2008, 320, 292-302. [CrossRef]

58. Mi, B.; Elimelech, M. Organic fouling of forward osmosis membranes: Fouling reversibility and cleaning without chemical reagents. J. Membr. Sci. 2010, 348, 337-345. [CrossRef]

59. Achilli, A.; Cath, T.Y.; Marchand, E.A.; Childress, A.E. The forward osmosis membrane bioreactor: A low fouling alternative to MBR processes. Desalination 2009, 239, 10-21. [CrossRef]

60. Lee, S.; Boo, C.; Elimelech, M.; Hong, S. Comparison of fouling behavior in forward osmosis (FO) and reverse osmosis (RO). J. Membr. Sci. 2010, 365, 34-39. [CrossRef]

61. Mi, B.; Elimelech, M. Silica scaling and scaling reversibility in forward osmosis. DES 2013, 312, 75-81. [CrossRef]

62. Kim, Y.; Elimelech, M.; Kyong, H.; Hong, S. Combined organic and colloidal fouling in forward osmosis: Fouling reversibility and the role of applied pressure. J. Membr. Sci. 2014, 460, 206-212. [CrossRef]

63. Marshall, A.D.; Munro, P.A.; Trägårdh, G. Influence of permeate flux on fouling during the microfiltration of $\beta$-lactoglobulin solutions under cross-flow conditions. J. Membr. Sci. 1997, 130, 23-30. [CrossRef]

64. Nguyen, T.; Kook, S.; Lee, C.; Field, R.W.; Kim, I.S. Critical flux-based membrane fouling control of forward osmosis: Behavior, sustainability, and reversibility. J. Membr. Sci. 2019, 570, 380-393. [CrossRef]

65. Xie, M.; Nghiem, L.D.; Price, W.E.; Elimelech, M. Comparison of the removal of hydrophobic trace organic contaminants by forward osmosis and reverse osmosis. Water Res. 2012, 46, 2683-2692. [CrossRef] [PubMed]

66. Liu, C.; Takagi, R.; Cheng, L.; Saeki, D.; Matsuyama, H. Enzyme-aided forward osmosis (E-FO) process to enhance removal of micropollutants from water resources. J. Membr. Sci. 2020, 593, 117399. [CrossRef]

67. Chung, T.S.; Li, X.; Ong, R.C.; Ge, Q.; Wang, H.; Han, G. Emerging forward osmosis (FO) technologies and challenges ahead for clean water and clean energy applications. Curr. Opin. Chem. Eng. 2012, 1, $246-257$. [CrossRef]

68. Arsalan, F.; She, Q.; Fane, A.G.; Field, R.W. Exploring the differences between forward osmosis and reverse osmosis fouling. J. Membr. Sci. 2018, 565, 241-253.

69. Zhang, J.; She, Q.; Chang, V.W.C.; Tang, C.Y.; Webster, R.D. Mining Nutrients (N, K, P) from Urban Source-Separated Urine by Forward Osmosis Dewatering. Environ. Sci. Technol. 2014, 48, 3386-3394. [CrossRef]

70. Phuntsho, S.; Kyong, H.; Hong, S.; Lee, S.; Vigneswaran, S. A novel low energy fertilizer driven forward osmosis desalination for direct fertigation: Evaluating the performance of fertilizer draw solutions. J. Membr. Sci. 2011, 375, 172-181. [CrossRef]

71. Mcgovern, R.K. On the potential of forward osmosis to energetically outperform reverse osmosis desalination. J. Membr. Sci. 2014, 469, 245-250. [CrossRef]

72. Cai, Y.; Hu, X.M. A critical review on draw solutes development for forward osmosis. Desalination 2016, 391, 16-29. [CrossRef]

73. Tang, C.Y.; She, Q.; Lay, W.C.L.; Wang, R.; Fane, A.G. Coupled effects of internal concentration polarization and fouling on flux behavior of forward osmosis membranes during humic acid filtration. J. Membr. Sci. 2010, 354, 123-133. [CrossRef]

74. Qi, S.; Qiu, C.Q.; Zhao, Y.; Tang, C.Y. Double-skinned forward osmosis membranes based on layer-by-layer assembly-FO performance and fouling behavior. J. Membr. Sci. 2012, 405, 20-29. [CrossRef]

75. Su, J.; Chung, T.S.; Helmer, B.J.; de Wit, J.S. Enhanced double-skinned FO membranes with inner dense layer for wastewater treatment and macromolecule recycle using Sucrose as draw solute. J. Membr. Sci. 2012, 396, 92-100. [CrossRef] 
76. McCutcheon, J.R.; Elimelech, M. Influence of concentrative and dilutive internal concentration polarization on flux behavior in forward osmosis. J. Membr. Sci. 2006, 284, 237-247. [CrossRef]

77. Zhang, S.; Wang, K.Y.; Chung, T.S.; Chen, H.; Jean, Y.C.; Amy, G. Well-constructed cellulose acetate membranes for forward osmosis: Minimized internal concentration polarization with an ultra-thin selective layer. J. Membr. Sci. 2010, 360, 522-535. [CrossRef]

78. Gao, Y.; Fang, Z.; Liang, P.; Huang, X. Direct concentration of municipal sewage by forward osmosis and membrane fouling behavior. Bioresour. Technol. 2018, 247, 730-735. [CrossRef]

79. Blandin, G.; Verliefde, A.R.D.; Comas, J.; Rodriguez-Roda, I.; Le-Clech, P. Efficiently combining water reuse and desalination through forward osmosis-reverse osmosis (FO-RO) hybrids: A critical review. Membranes 2016, 6, 36. [CrossRef]

80. Pan, S.F.; Dong, Y.; Zheng, Y.M.; Zhong, L.B.; Yuan, Z.H. Self-sustained hydrophilic nanofiber thin film composite forward osmosis membranes: Preparation, characterization and application for simulated antibiotic wastewater treatment. J. Membr. Sci. 2017, 523, 205-215. [CrossRef]

81. Kravath, R.E.; Davis, J.A. Desalination of sea water by direct osmosis. Desalination 1975, 16, 151-155. [CrossRef]

82. Zhao, S.; Zou, L.; Mulcahy, D. Brackish water desalination by a hybrid forward osmosis-nanofiltration system using divalent draw solute. Desalination 2012, 284, 175-181. [CrossRef]

83. McCutcheon, J.R.; McGinnis, R.L.; Elimelech, M. Desalination by ammonia-carbon dioxide forward osmosis: Influence of draw and feed solution concentrations on process performance. J. Membr. Sci. 2006, 278, 114-123. [CrossRef]

84. McCutcheon, J.R.; McGinnis, R.L.; Elimelech, M. A novel ammonia-carbon dioxide forward (direct) osmosis desalination process. Desalination 2005, 174, 1-11. [CrossRef]

85. Rastogi, N.K. Opportunities and Challenges in Application of Forward Osmosis in Food Processing. Crit. Rev. Food Sci. Nutr. 2016, 56, 266-291. [CrossRef]

86. Dova, M.I.; Petrotos, K.B.; Lazarides, H.N. On the direct osmotic concentration of liquid foods: Part II. Development of a generalized model. J. Food Eng. 2007, 78, 431-437. [CrossRef]

87. Terefe, N.S.; Janakievski, F.; Glagovskaia, O.; De Silva, K.; Horne, M.; Stockmann, R. Forward Osmosis: A Novel Membrane Separation Technology of Relevance to Food and Related Industries; Elsevier: Amsterdam, The Netherlands, 2016; ISBN 9780081002988.

88. Popper, K.; Camirand, W.M.; Nury, F.; Stanley, W.L. Stanley Dialyzer concentrates beverages. Food Eng. 1966, 38, 102-104.

89. Chanukya, B.S.; Rastogi, N.K. A Comparison of Thermal Processing, Freeze Drying and Forward Osmosis for the Downstream Processing of Anthocyanin from Rose Petals. J. Food Process. Preserv. 2016, 40, 1289-1296. [CrossRef]

90. Singh, N.; Petrinic, I.; Hélix-Nielsen, C.; Basu, S.; Balakrishnan, M. Concentrating molasses distillery wastewater using biomimetic forward osmosis (FO) membranes. Water Res. 2018, 130, 271-280. [CrossRef]

91. Wang, Y.N.; Wang, R.; Li, W.; Tang, C.Y. Whey recovery using forward osmosis-Evaluating the factors limiting the flux performance. J. Membr. Sci. 2017, 533, 179-189. [CrossRef]

92. Madhumala, M.; Moulik, S.; Sankarshana, T.; Sridhar, S. Forward-osmosis-aided concentration of fructose sugar through hydrophilized polyamide membrane: Molecular modeling and economic estimation. J. Appl. Polym. Sci. 2017, 134, 1-12. [CrossRef]

93. Han, G.; Chan, S.S.; Chung, T.S. Forward Osmosis (FO) for Water Reclamation from Emulsified Oil/Water Solutions: Effects of Membrane and Emulsion Characteristics. ACS Sustain. Chem. Eng. 2016, 4, 5021-5032. [CrossRef]

94. Chun, Y.; Kim, S.J.; Millar, G.J.; Mulcahy, D.; Kim, I.S.; Zou, L. Forward osmosis as a pre-treatment for treating coal seam gas associated water: Flux and fouling behaviour. Desalination 2017, 403, 144-152. [CrossRef]

95. Liu, C.; Lei, X.; Wang, L.; Jia, J.; Liang, X.; Zhao, X.; Zhu, H. Investigation on the removal performances of heavy metal ions with the layer-by-layer assembled forward osmosis membranes. Chem. Eng. J. 2017, 327, 60-70. [CrossRef]

96. You, S.; Lu, J.; Tang, C.Y.; Wang, X. Rejection of heavy metals in acidic wastewater by a novel thin-film inorganic forward osmosis membrane. Chem. Eng. J. 2017, 320, 532-538. [CrossRef] 
97. Vital, B.; Bartacek, J.; Ortega-Bravo, J.C.; Jeison, D. Treatment of acid mine drainage by forward osmosis: Heavy metal rejection and reverse flux of draw solution constituents. Chem. Eng. J. 2018, 332, 85-91. [CrossRef]

98. Sivertsen, E.; Holt, T.; Thelin, W.; Brekke, G. Pressure retarded osmosis efficiency for different hollow fibre membrane module flow configurations. Desalination 2013, 312, 107-123. [CrossRef]

99. Allegrezza, A.E.; Burchesky, R.D.; Götz, G.; Davis, R.B.; Coplan, M.J. Hollow fiber composite reverse osmosis membrane. Desalination 1977, 20, 87-94. [CrossRef]

100. Li, S.G.; Koops, G.H.; Mulder, M.H.V.; van den Boomgaard, T.; Smolders, C.A. Wet spinning of integrally skinned hollow fiber membranes by a modified dual-bath coagulation method using a triple orifice spinneret. J. Membr. Sci. 1994, 94, 329-340. [CrossRef]

101. Hey, T.; Bajraktari, N.; Davidsson, Å.; Vogel, J.; Madsen, H.T.; Hélix-Nielsen, C.; Jansen, J.L.C.; Jönsson, K. Evaluation of direct membrane filtration and direct forward osmosis as concepts for compact and energy-positive municipal wastewater treatment. Environ. Technol. 2018, 39, 264-276. [CrossRef]

102. Sant'Anna, V.; Marczak, L.D.F.; Tessaro, I.C. Membrane concentration of liquid foods by forward osmosis: Process and quality view. J. Food Eng. 2012, 111, 483-489. [CrossRef]

103. Barros, A.I.R.N.A.; Nunes, F.M.; Gonçalves, B.; Bennett, R.N.; Silva, A.P. Effect of cooking on total vitamin C contents and antioxidant activity of sweet chestnuts (Castanea sativa Mill.). Food Chem. 2011, 128, 165-172. [CrossRef] [PubMed]

104. Mohammad, A.W.; Ng, C.Y.; Lim, Y.P.; Ng, G.H. Ultrafiltration in Food Processing Industry: Review on Application, Membrane Fouling, and Fouling Control. Food Bioprocess Technol. 2012, 5, 1143-1156. [CrossRef]

105. Sanahuja-Embuena, V.; Khensir, G.; Yusuf, M.; Andersen, M.F.; Nguyen, X.T.; Trzaskus, K.; Pinelo, M.; Helix-Nielsen, C. Role of operating conditions in a pilot scale investigation of hollow fiber forward osmosis membrane modules. Membranes 2019, 9, 66. [CrossRef] [PubMed]

106. Yang, E.; Kim, C.M.; Song, J.H.; Ki, H.; Ham, M.H.; Kim, I.S. Enhanced desalination performance of forward osmosis membranes based on reduced graphene oxide laminates coated with hydrophilic polydopamine. Carbon 2017, 117, 293-300. [CrossRef]

107. Qiu, C.; Setiawan, L.; Wang, R.; Tang, C.Y.; Fane, A.G. High performance flat sheet forward osmosis membrane with an NF-like selective layer on a woven fabric embedded substrate. Desalination 2012, 287, 266-270. [CrossRef]

108. Werber, J.R.; Deshmukh, A.; Elimelech, M. The Critical Need for Increased Selectivity, Not Increased Water Permeability, for Desalination Membranes. Environ. Sci. Technol. Lett. 2016, 3, 112-120. [CrossRef]

109. Ge, Q.; Ling, M.; Chung, T.-S. Draw solutions for forward osmosis processes: Developments, challenges, and prospects for the future. J. Membr. Sci. 2013, 442, 225-237. [CrossRef]

110. Achilli, A.; Cath, T.Y.; Childress, A.E. Selection of inorganic-based draw solutions for forward osmosis applications. J. Membr. Sci. 2010, 364, 233-241. [CrossRef]

111. Luo, H.; Wang, Q.; Zhang, T.C.; Tao, T.; Zhou, A.; Chen, L.; Bie, X. A review on the recovery methods of draw solutes in forward osmosis. J. Water Process Eng. 2014, 4, 212-223. [CrossRef]

112. Chekli, L.; Phuntsho, S.; Shon, H.K.; Vigneswaran, S.; Kandasamy, J.; Chanan, A. A review of draw solutes in forward osmosis process and their use in modern applications. Desalin. Water Treat. 2012, 43, 167-184. [CrossRef]

113. Bui, N.N.; Arena, J.T.; McCutcheon, J.R. Proper accounting of mass transfer resistances in forward osmosis: Improving the accuracy of model predictions of structural parameter. J. Membr. Sci. 2015, 492, 289-302. [CrossRef]

114. Ren, J.; Chowdhury, M.R.; Qi, J.; Xia, L.; Huey, B.D.; McCutcheon, J.R. Relating osmotic performance of thin film composite hollow fiber membranes to support layer surface pore size. J. Membr. Sci. 2017, 540, 344-353. [CrossRef]

115. Altaee, A.; Braytee, A.; Millar, G.J.; Naji, O. Energy efficiency of hollow fibre membrane module in the forward osmosis seawater desalination process. J. Membr. Sci. 2019, 587, 117165. [CrossRef]

116. Lotfi, F.; Phuntsho, S.; Majeed, T.; Kim, K.; Han, D.S.; Abdel-Wahab, A.; Shon, H.K. Thin film composite hollow fibre forward osmosis membrane module for the desalination of brackish groundwater for fertigation. Desalination 2015, 364, 108-118. [CrossRef] 
117. Li, P.; Lim, S.S.; Neo, J.G.; Ong, R.C.; Weber, M.; Staudt, C.; Widjojo, N.; Maletzko, C.; Chung, T.S. Short- and Long-Term Performance of the Thin-Film Composite Forward Osmosis (TFC-FO) Hollow Fiber Membranes for Oily Wastewater Purification. Ind. Eng. Chem. Res. 2014, 53, 14056-14064. [CrossRef]

118. Yabuno, Y.; Mihara, K.; Komatsu, K.; Shimamura, S.; Nakagawa, K.; Shintani, T.; Matsuyama, H.; Yoshioka, T. Preparation of Polyamide Thin-Film Composite Membranes Using Hydrophilic Hollow Fiber PVDF via the TIPS Process Modified by PVA Diffusion. Ind. Eng. Chem. Res. 2019, 58, 21691-21699. [CrossRef]

119. Zhao, S.; Minier-Matar, J.; Chou, S.; Wang, R.; Fane, A.G.; Adham, S. Gas field produced/process water treatment using forward osmosis hollow fiber membrane: Membrane fouling and chemical cleaning. Desalination 2017, 402, 143-151. [CrossRef]

120. Arkhangelsky, E.; Wicaksana, F.; Tang, C.; Al-Rabiah, A.A.; Al-Zahrani, S.M.; Wang, R. Combined organic-inorganic fouling of forward osmosis hollow fiber membranes. Water Res. 2012, 46, 6329-6338. [CrossRef]

121. Li, X.; Loh, C.H.; Wang, R.; Widjajanti, W.; Torres, J. Fabrication of a robust high-performance FO membrane by optimizing substrate structure and incorporating aquaporin into selective layer. J. Memb. Sci. 2017, 525, 257-268. [CrossRef]

122. Nikbakht Fini, M.; Madsen, H.T.; Sørensen, J.L.; Muff, J. Moving from lab to pilot scale in forward osmosis for pesticides rejection using aquaporin membranes. Sep. Purif. Technol. 2020, 240, 116616. [CrossRef]

123. Shibuya, M.; Yasukawa, M.; Takahashi, T.; Miyoshi, T.; Higa, M.; Matsuyama, H. Effect of operating conditions on osmotic-driven membrane performances of cellulose triacetate forward osmosis hollow fiber membrane. Desalination 2015, 362, 34-42. [CrossRef]

124. Su, J.; Chung, T.-S.; Helmer, B.J.; de Wit, J.S. Understanding of low osmotic efficiency in forward osmosis: Experiments and modeling. Desalination 2013, 313, 156-165. [CrossRef]

125. Ren, J.; McCutcheon, J.R. A new commercial biomimetic hollow fiber membrane for forward osmosis. Desalination 2018, 442, 44-50. [CrossRef]

126. Li, Y.; Zhao, S.; Setiawan, L.; Zhang, L.; Wang, R. Integral hollow fiber membrane with chemical cross-linking for pressure retarded osmosis operated in the orientation of active layer facing feed solution. J. Membr. Sci. 2018, 550, 163-172. [CrossRef]

127. Lim, S.; Tran, V.H.; Akther, N.; Phuntsho, S.; Shon, H.K. Defect-free outer-selective hollow fiber thin-film composite membranes for forward osmosis applications. J. Membr. Sci. 2019, 586, 281-291. [CrossRef]

128. Li, X.; Ang, W.L.; Liu, Y.; Chung, T.-S. Engineering design of outer-selective tribore hollow fiber membranes for forward osmosis and oil-water separation. AIChE J. 2015, 61, 4491-4501. [CrossRef]

129. Luo, L.; Wang, P.; Zhang, S.; Han, G.; Chung, T.-S. Novel thin-film composite tri-bore hollow fiber membrane fabrication for forward osmosis. J. Membr. Sci. 2014, 461, 28-38. [CrossRef]

130. Ren, J.; McCutcheon, J.R. Polyacrylonitrile supported thin film composite hollow fiber membranes for forward osmosis. Desalination 2015, 372, 67-74. [CrossRef]

131. Mohammad, A.W.; Teow, Y.H.; Ang, W.L.; Chung, Y.T.; Oatley-Radcliffe, D.L.; Hilal, N. Nanofiltration membranes review: Recent advances and future prospects. Desalination 2015, 356, 226-254. [CrossRef]

132. Wittbecker, E.L.; Morgan, P.W. Interfacial polycondensation. J. Polym. Sci. 1959, 40, 289-297. [CrossRef]

133. Morgan, P.W.; Kwolek, S.L. Interfacial polycondensation. II. Fundamentals of polymer formation at liquid interfaces. J. Polym. Sci. 1959, 40, 299-327. [CrossRef]

134. Cadotte, J.E.; Petersen, R.J.; Larson, R.E.; Erickson, E.E. A new thin-film composite seawater reverse osmosis membrane. Desalination 1980, 32, 25-31. [CrossRef]

135. Raaijmakers, M.J.T.; Benes, N.E. Current trends in interfacial polymerization chemistry. Prog. Polym. Sci. 2016, 63, 86-142. [CrossRef]

136. Yip, N.Y.; Tiraferri, A.; Phillip, W.A.; Schiffman, J.D.; Elimelech, M. High Performance Thin-Film Composite Forward Osmosis Membrane. Environ. Sci. Technol. 2010, 44, 3812-3818. [CrossRef]

137. Alsvik, I.L.; Hägg, M.B. Pressure retarded osmosis and forward osmosis membranes: Materials and methods. Polymers 2013, 5, 303-327. [CrossRef]

138. Freger, V. Nanoscale Heterogeneity of Polyamide Membranes Formed by Interfacial Polymerization. Langmuir 2003, 19, 4791-4797. [CrossRef]

139. Freger, V.; Srebnik, S. Mathematical model of charge and density distributions in interfacial polymerization of thin films. J. Appl. Polym. Sci. 2003, 88, 1162-1169. [CrossRef] 
140. Ghosh, A.K.; Hoek, E.M.V. Impacts of support membrane structure and chemistry on polyamide-polysulfone interfacial composite membranes. J. Membr. Sci. 2009, 336, 140-148. [CrossRef]

141. Singh, P.S.; Joshi, S.V.; Trivedi, J.J.; Devmurari, C.V.; Rao, A.P.; Ghosh, P.K. Probing the structural variations of thin film composite RO membranes obtained by coating polyamide over polysulfone membranes of different pore dimensions. J. Membr. Sci. 2006, 278, 19-25. [CrossRef]

142. Wang, W.; Li, G. One-step fabrication of high selective hollow fiber nanofiltration membrane module. Fibers Polym. 2010, 11, 1041-1048. [CrossRef]

143. Ahmad, A.L.; Ooi, B.S.; Choudhury, J.P. Effect of Hydrophilization Additive and Reaction Time on Separation Properties of Polyamide Nanofiltration Membrane. Sep. Sci. Technol. 2005, 39, 1815-1831. [CrossRef]

144. Foglia, F.; Karan, S.; Nania, M.; Jiang, Z.; Porter, A.E.; Barker, R.; Livingston, A.G.; Cabral, J.T. Neutron Reflectivity and Performance of Polyamide Nanofilms for Water Desalination. Adv. Funct. Mater. 2017, 27, 1701738. [CrossRef]

145. Xie, W.; Geise, G.M.; Freeman, B.D.; Lee, H.; Byun, G.; McGrath, J.E. Polyamide interfacial composite membranes prepared from $\mathrm{m}$-phenylene diamine, trimesoyl chloride and a new disulfonated diamine. $J$. Membr. Sci. 2012, 403, 152-161. [CrossRef]

146. Zhang, Q.; Zhang, Z.; Dai, L.; Wang, H.; Li, S.; Zhang, S. Novel insights into the interplay between support and active layer in the thin fi lm composite polyamide membranes. J. Membr. Sci. 2017, 537, 372-383. [CrossRef]

147. Ma, D.; Peh, S.B.; Han, G.; Chen, S.B. Thin-Film Nanocomposite (TFN) Membranes Incorporated with Super-Hydrophilic Metal-Organic Framework (MOF) UiO-66: Toward Enhancement of Water Flux and Salt Rejection. ACS Appl. Mater. Interfaces 2017, 9, 7523-7534. [CrossRef]

148. Amini, M.; Jahanshahi, M.; Rahimpour, A. Synthesis of novel thin film nanocomposite (TFN) forward osmosis membranes using functionalized multi-walled carbon nanotubes. J. Membr. Sci. 2013, 435, $233-241$. [CrossRef]

149. Goh, K.; Setiawan, L.; Wei, L.; Jiang, W.; Wang, R.; Chen, Y. Fabrication of novel functionalized multi-walled carbon nanotube immobilized hollow fiber membranes for enhanced performance in forward osmosis process. J. Membr. Sci. 2013, 446, 244-254. [CrossRef]

150. Wang, H.; Chung, T.S.; Tong, Y.W.; Jeyaseelan, K.; Armugam, A.; Chen, Z.; Hong, M.; Meier, W. Highly permeable and selective pore-spanning biomimetic membrane embedded with aquaporin Z. Small 2012, 8, 1185-1190. [CrossRef]

151. Xia, L.; Andersen, M.F.; Hélix-Nielsen, C.; McCutcheon, J.R. Novel Commercial Aquaporin Flat-Sheet Membrane for Forward Osmosis. Ind. Eng. Chem. Res. 2017, 56, 11919-11925. [CrossRef]

152. Xie, W.; He, F.; Wang, B.; Chung, T.-S.; Jeyaseelan, K.; Armugam, A.; Tong, Y.W. An aquaporin-based vesicle-embedded polymeric membrane for low energy water filtration. J. Mater. Chem. 2013, 1, 7592. [CrossRef]

153. Saren, Q.; Qiu, C.Q.; Tang, C.Y. Synthesis and Characterization of Novel Forward Osmosis Membranes based on Layer-by-Layer Assembly. Environ. Sci. Technol. 2011, 45, 5201-5208. [CrossRef] [PubMed]

154. Qiu, C.; Qi, S.; Tang, C.Y. Synthesis of high flux forward osmosis membranes by chemically crosslinked layer-by-layer polyelectrolytes. J. Membr. Sci. 2011, 381, 74-80. [CrossRef]

155. Duong, P.H.H.; Zuo, J.; Chung, T.-S. Highly crosslinked layer-by-layer polyelectrolyte FO membranes: Understanding effects of salt concentration and deposition time on FO performance. J. Membr. Sci. 2013, 427, 411-421. [CrossRef]

156. Liu, C.; Fang, W.; Chou, S.; Shi, L.; Fane, A.G.; Wang, R. Fabrication of layer-by-layer assembled FO hollow fiber membranes and their performances using low concentration draw solutions. Desalination 2013, 308, 147-153. [CrossRef]

157. Joseph, N.; Ahmadiannamini, P.; Hoogenboom, R.; Vankelecom, I.F.J. Layer-by-layer preparation of polyelectrolyte multilayer membranes for separation. Polym. Chem. 2014, 5, 1817-1831. [CrossRef]

158. de Grooth, J.; Reurink, D.M.; Ploegmakers, J.; de Vos, W.M.; Nijmeijer, K. Charged Micropollutant Removal With Hollow Fiber Nanofiltration Membranes Based On Polycation/Polyzwitterion/Polyanion Multilayers. ACS Appl. Mater. Interfaces 2014, 6, 17009-17017. [CrossRef]

159. Bertrand, P.; Jonas, A.; Laschewsky, A.; Legras, R. Ultrathin polymer coatings by complexation of polyelectrolytes at interfaces: Suitable materials, structure and properties. Macromol. Rapid Commun. 2000, 21, 319-348. [CrossRef] 
160. Deng, H.-Y.; Xu, Y.-Y.; Zhu, B.-K.; Wei, X.-Z.; Liu, F.; Cui, Z.-Y. Polyelectrolyte membranes prepared by dynamic self-assembly of poly (4-styrenesulfonic acid-co-maleic acid) sodium salt (PSSMA) for nanofiltration (I). J. Membr. Sci. 2008, 323, 125-133. [CrossRef]

161. Ouyang, L.; Malaisamy, R.; Bruening, M.L. Multilayer polyelectrolyte films as nanofiltration membranes for separating monovalent and divalent cations. J. Membr. Sci. 2008, 310, 76-84. [CrossRef]

162. Park, J.; Park, J.; Kim, S.H.; Cho, J.; Bang, J. Desalination membranes from pH-controlled and thermally-crosslinked layer-by-layer assembled multilayers. J. Mater. Chem. 2010, 20, 2085-2091. [CrossRef]

163. Setiawan, L.; Wang, R.; Li, K.; Fane, A.G. Fabrication and characterization of forward osmosis hollow fiber membranes with antifouling NF-like selective layer. J. Membr. Sci. 2012, 394, 80-88. [CrossRef]

164. Kang, Y.; Zheng, S.; Finnerty, C.; Lee, M.J.; Mi, B. Regenerable Polyelectrolyte Membrane for Ultimate Fouling Control in Forward Osmosis. Environ. Sci. Technol. 2017, 51, 3242-3249. [CrossRef]

165. Asadi Tashvigh, A.; Chung, T.-S. Facile fabrication of solvent resistant thin film composite membranes by interfacial crosslinking reaction between polyethylenimine and dibromo-p-xylene on polybenzimidazole substrates. J. Membr. Sci. 2018, 560, 115-124. [CrossRef]

166. Emadzadeh, D.; Lau, W.J.; Matsuura, T.; Ismail, A.F.; Rahbari-Sisakht, M. Synthesis and characterization of thin film nanocomposite forward osmosis membrane with hydrophilic nanocomposite support to reduce internal concentration polarization. J. Membr. Sci. 2014, 449, 74-85. [CrossRef]

167. Emadzadeh, D.; Lau, W.J.; Matsuura, T.; Rahbari-Sisakht, M.; Ismail, A.F. A novel thin film composite forward osmosis membrane prepared from PSf-TiO2nanocomposite substrate for water desalination. Chem. Eng. J. 2014, 237, 70-80. [CrossRef]

168. Wang, Y.; Ou, R.; Ge, Q.; Wang, H.; Xu, T. Preparation of polyethersulfone/carbon nanotube substrate for high-performance forward osmosis membrane. Desalination 2013, 330, 70-78. [CrossRef]

169. Ma, N.; Wei, J.; Qi, S.; Zhao, Y.; Gao, Y.; Tang, C.Y. Nanocomposite substrates for controlling internal concentration polarization in forward osmosis membranes. J. Membr. Sci. 2013, 441, 54-62. [CrossRef]

170. Wang, Y.; Ou, R.; Wang, H.; Xu, T. Graphene oxide modified graphitic carbon nitride as a modifier for thin film composite forward osmosis membrane. J. Membr. Sci. 2015, 475, 281-289. [CrossRef]

171. Sun, W.; Shi, J.; Chen, C.; Li, N.; Xu, Z.; Li, J.; Lv, H.; Qian, X.; Zhao, L. A review on organic-inorganic hybrid nanocomposite membranes: A versatile tool to overcome the barriers of forward osmosis. RSC Adv. 2018, 8, 10040-10056. [CrossRef]

172. Kim, J.; Van Der Bruggen, B. The use of nanoparticles in polymeric and ceramic membrane structures: Review of manufacturing procedures and performance improvement for water treatment. Environ. Pollut. 2010, 158, 2335-2349. [CrossRef]

173. Kato, K.; Uchida, E.; Kang, E.T.; Uyama, Y.; Ikada, Y. Polymer surface with graft chains. Prog. Polym. Sci. 2003, 28, 209-259. [CrossRef]

174. Wang, J.; Xiao, T.; Bao, R.; Li, T.; Wang, Y.; Li, D.; Li, X.; He, T. Zwitterionic surface modification of forward osmosis membranes using $\mathrm{N}$-aminoethyl piperazine propane sulfonate for grey water treatment. Process Saf. Environ. Prot. 2018, 116, 632-639. [CrossRef]

175. Hegab, H.M.; ElMekawy, A.; Barclay, T.G.; Michelmore, A.; Zou, L.; Saint, C.P.; Ginic-Markovic, M. Fine-Tuning the Surface of Forward Osmosis Membranes via Grafting Graphene Oxide: Performance Patterns and Biofouling Propensity. ACS Appl. Mater. Interfaces 2015, 7, 18004-18016. [CrossRef]

176. Roth, H.; Luelf, T.; Koppelmann, A.; Abel, M.; Wessling, M. Chemistry in a spinneret—Composite hollow fiber membranes in a single step process. J. Membr. Sci. 2018, 554, 48-58. [CrossRef]

177. Yang, Q.; Wang, K.Y.; Chung, T.S. Dual-layer hollow fibers with enhanced flux as novel forward osmosis membranes for water production. Environ. Sci. Technol. 2009, 43, 2800-2805. [CrossRef]

178. Dutczak, S.M.; Tanardi, C.R.; Kopeć, K.K.; Wessling, M.; Stamatialis, D. "Chemistry in a spinneret" to fabricate hollow fibers for organic solvent filtration. Sep. Purif. Technol. 2012, 86, 183-189. [CrossRef]

179. Gherasim, C.V.; Luelf, T.; Roth, H.; Wessling, M. Dual-Charged Hollow Fiber Membranes for Low-Pressure Nanofiltration Based on Polyelectrolyte Complexes: One-Step Fabrication with Tailored Functionalities. ACS Appl. Mater. Interfaces 2016, 8, 19145-19157. [CrossRef]

180. Mulder, M. Basic Principles of Membrane Technology; Kluwer Academic Publishers: Berlin, Germany, 1996; ISBN 9780792309789.

181. Liu, F.; Hashim, N.A.; Liu, Y.; Abed, M.R.M.; Li, K. Progress in the production and modification of PVDF membranes. J. Membr. Sci. 2011, 375, 1-27. [CrossRef] 
182. Mehta, G.D.; Loeb, S. Internal polarization in the porous substructure of a semipermeable membrane under pressure-retarded osmosis. J. Membr. Sci. 1978, 4, 261-265. [CrossRef]

183. Loeb, S.; Titelman, L.; Korngold, E.; Freiman, J. Effect of porous support fabric on osmosis through a Loeb-Sourirajan type asymmetric membrane. J. Membr. Sci. 1997, 129, 243-249. [CrossRef]

184. Sablani, S.; Goosen, M.; Al-Belushi, R.; Wilf, M. Concentration polarization in ultrafiltration and reverse osmosis: A critical review. Desalination 2001, 141, 269-289. [CrossRef]

185. Akther, N.; Sodiq, A.; Giwa, A.; Daer, S.; Arafat, H.A.; Hasan, S.W. Recent advancements in forward osmosis desalination: A review. Chem. Eng. J. 2015, 281, 502-522. [CrossRef]

186. Gray, G.T.; McCutcheon, J.R.; Elimelech, M. Internal concentration polarization in forward osmosis: Role of membrane orientation. Desalination 2006, 197, 1-8. [CrossRef]

187. McCutcheon, J.R.; Elimelech, M. Influence of membrane support layer hydrophobicity on water flux in osmotically driven membrane processes. J. Membr. Sci. 2008, 318, 458-466. [CrossRef]

188. Wei, J.; Liu, X.; Qiu, C.; Wang, R.; Tang, C.Y. Influence of monomer concentrations on the performance of polyamide-based thin film composite forward osmosis membranes. J. Membr. Sci. 2011, 381, 110-117. [CrossRef]

189. Jung, D.H.; Lee, J.; Kim, D.Y.; Lee, Y.G.; Park, M.; Lee, S.; Yang, D.R.; Kim, J.H. Simulation of forward osmosis membrane process: Effect of membrane orientation and flow direction of feed and draw solutions. Desalination 2011, 277, 83-91. [CrossRef]

190. Chanukya, B.S.; Patil, S.; Rastogi, N.K. Influence of concentration polarization on flux behavior in forward osmosis during desalination using ammonium bicarbonate. Desalination 2013, 312, 39-44. [CrossRef]

191. Puguan, J.M.C.; Kim, H.-S.; Lee, K.-J.; Kim, H. Low internal concentration polarization in forward osmosis membranes with hydrophilic crosslinked PVA nanofibers as porous support layer. Desalination 2014, 336, 24-31. [CrossRef]

192. Tiraferri, A.; Yip, N.Y.; Straub, A.P.; Romero-Vargas Castrillon, S.; Elimelech, M. A method for the simultaneous determination of transport and structural parameters of forward osmosis membranes. J. Membr. Sci. 2013, 444, 523-538. [CrossRef]

193. Bartels, C.; Franks, R.; Rybar, S.; Schierach, M.; Wilf, M. The effect of feed ionic strength on salt passage through reverse osmosis membranes. Desalination 2005, 184, 185-195. [CrossRef]

194. Cath, T.Y.; Elimelech, M.; McCutcheon, J.R.; McGinnis, R.L.; Achilli, A.; Anastasio, D.; Brady, A.R.; Childress, A.E.; Farr, I.V.; Hancock, N.T.; et al. Standard Methodology for Evaluating Membrane Performance in Osmotically Driven Membrane Processes. Desalination 2013, 312, 31-38. [CrossRef]

195. Chi, X.Y.; Zhang, P.Y.; Guo, X.J.; Xu, Z.L. A novel TFC forward osmosis (FO) membrane supported by polyimide (PI) microporous nanofiber membrane. Appl. Surf. Sci. 2018, 427, 1-9. [CrossRef]

196. Manickam, S.S.; McCutcheon, J.R. Model thin film composite membranes for forward osmosis: Demonstrating the inaccuracy of existing structural parameter models. J. Membr. Sci. 2015, 483, 70-74. [CrossRef]

197. Huang, L.; McCutcheon, J.R. Impact of support layer pore size on performance of thin film composite membranes for forward osmosis. J. Membr. Sci. 2015, 483, 25-33. [CrossRef]

198. Widjojo, N.; Chung, T.S.; Weber, M.; Maletzko, C.; Warzelhan, V. The role of sulphonated polymer and macrovoid-free structure in the support layer for thin-film composite (TFC) forward osmosis (FO) membranes. J. Membr. Sci. 2011, 383, 214-223. [CrossRef]

199. Tiraferri, A.; Yip, N.Y.; Phillip, W.A.; Schiffman, J.D.; Elimelech, M. Relating performance of thin-film composite forward osmosis membranes to support layer formation and structure. J. Membr. Sci. 2011, 367, 340-352. [CrossRef]

200. Wei, J.; Qiu, C.; Tang, C.Y.; Wang, R.; Fane, A.G. Synthesis and characterization of flat-sheet thin film composite forward osmosis membranes. J. Membr. Sci. 2011, 372, 292-302. [CrossRef]

201. Arena, J.T.; McCloskey, B.; Freeman, B.D.; McCutcheon, J.R. Surface modification of thin film composite membrane support layers with polydopamine: Enabling use of reverse osmosis membranes in pressure retarded osmosis. J. Membr. Sci. 2011, 375, 55-62. [CrossRef]

202. Zuo, H.R.; Fu, J.B.; Cao, G.P.; Hu, N.; Lu, H.; Liu, H.Q.; Chen, P.P.; Yu, J. The effects of surface-charged submicron polystyrene particles on the structure and performance of PSF forward osmosis membrane. Appl. Surf. Sci. 2018, 436, 1181-1192. [CrossRef]

203. Fan, X.; Liu, Y.; Quan, X. A novel reduced graphene oxide/carbon nanotube hollow fiber membrane with high forward osmosis performance. Desalination 2019, 451, 117-124. [CrossRef] 
204. Chen, G.; Li, X.-M.; Huang, M.; He, T. Concentrating underground brine using a TFC hollow fiber forward osmosis membrane: Effects of cleaning. Environ. Sci. Water Res. Technol. 2018, 4, 851-862. [CrossRef]

205. Zhou, Z.; Lee, J.Y.; Chung, T.-S. Thin film composite forward-osmosis membranes with enhanced internal osmotic pressure for internal concentration polarization reduction. Chem. Eng. J. 2014, 249, 236-245. [CrossRef]

206. Wong, M.C.Y.; Martinez, K.; Ramon, G.Z.; Hoek, E.M. Impacts of operating conditions and solution chemistry on osmotic membrane structure and performance. Desalination 2012, 287, 340-349. [CrossRef]

207. Bui, N.-N. Engineered Osmosis for Sustainable Water and Energy: Novel Nanofiber-Supported Thin-Film Composite Membrane Design E Updated Flux Model Proposal; University of Connecticut: Storrs, CT, USA, 2013.

208. Cornelissen, E.R.; Harmsen, D.; de Korte, K.F.; Ruiken, C.J.; Qin, J.J.; Oo, H.; Wessels, L.P. Membrane fouling and process performance of forward osmosis membranes on activated sludge. J. Membr. Sci. 2008, 319, 158-168. [CrossRef]

209. Krull, F.F.; Fritzmann, C.; Melin, T. Liquid membranes for gas/vapor separations. J. Membr. Sci. 2008, 325, 509-519. [CrossRef]

210. Song, X.; Liu, Z.; Sun, D.D. Nano gives the answer: Breaking the bottleneck of internal concentration polarization with a nanofiber composite forward osmosis membrane for a high water production rate. Adv. Mater. 2011, 23, 3256-3260. [CrossRef]

211. Djian, D.; Alloin, F.; Martinet, S.; Lignier, H.; Sanchez, J.Y. Lithium-ion batteries with high charge rate capacity: Influence of the porous separator. J. Power Sources 2007, 172, 416-421. [CrossRef]

212. Iversen, S.B.; Bhatia, V.K.; Dam-Johansen, K.; Jonsson, G. Characterization of microporous membranes for use in membrane contactors. J. Membr. Sci. 1997, 130, 205-217. [CrossRef]

213. Adnan, S.; Hoang, M.; Wang, H.; Xie, Z. Commercial PTFE membranes for membrane distillation application: Effect of microstructure and support material. Desalination 2012, 284, 297-308. [CrossRef]

214. El Aamrani, F.Z.; Kumar, A.; Beyer, L.; Florido, A.; Sastre, A.M. Mechanistic study of active transport of silver(I) using sulfur containing novel carriers across a liquid membrane. J. Membr. Sci. 1999, 152, 263-275. [CrossRef]

215. Park, S.W.; Heo, N.H.; Kim, G.W.; Sohn, I.J.; Kumazawa, H. Facilitated transport of carbon dioxide through an immobilized liquid membrane of aqueous carbonate solution with additives. Sep. Sci. Technol. 2000, 35, 2497-2512. [CrossRef]

216. Teramoto, M.; Huang, Q.; Maki, T.; Matsuyama, H. Facilitated transport of SO2 through supported liquid membrane using water as a carrier. Sep. Purif. Technol. 1999, 16, 109-118. [CrossRef]

217. Wolf, J.R.; Strieder, W. Surface and void tortuosities for a random fiber bed: Overlapping, parallel cylinders of several radii. J. Membr. Sci. 1990, 49, 103-115. [CrossRef]

218. Alves, V.D.; Coelhoso, I.M. Effect of membrane characteristics on mass and heat transfer in the osmotic evaporation process. J. Membr. Sci. 2004, 228, 159-167. [CrossRef]

219. Allaire-Leung, S.E.; Gupta, S.C.; Moncrief, J.F. Water and solute movement in soil as influenced by macropore characteristics: 2. Macropore tortuosity. J. Contam. Hydrol. 2000, 41, 303-315. [CrossRef]

220. Boving, T.B.; Grathwohl, P. Tracer diffusion coefficients in sedimentary rocks: Correlation to porosity and hydraulic conductivity. J. Contam. Hydrol. 2001, 53, 85-100. [CrossRef]

221. Ghanbarian, B.; Hunt, A.G.; Ewing, R.P.; Sahimi, M. Tortuosity in Porous Media: A Critical Review. Soil Sci. Soc. Am. J. 2013, 77, 1461-1477. [CrossRef]

(C) 2020 by the authors. Licensee MDPI, Basel, Switzerland. This article is an open access article distributed under the terms and conditions of the Creative Commons Attribution (CC BY) license (http://creativecommons.org/licenses/by/4.0/). 